
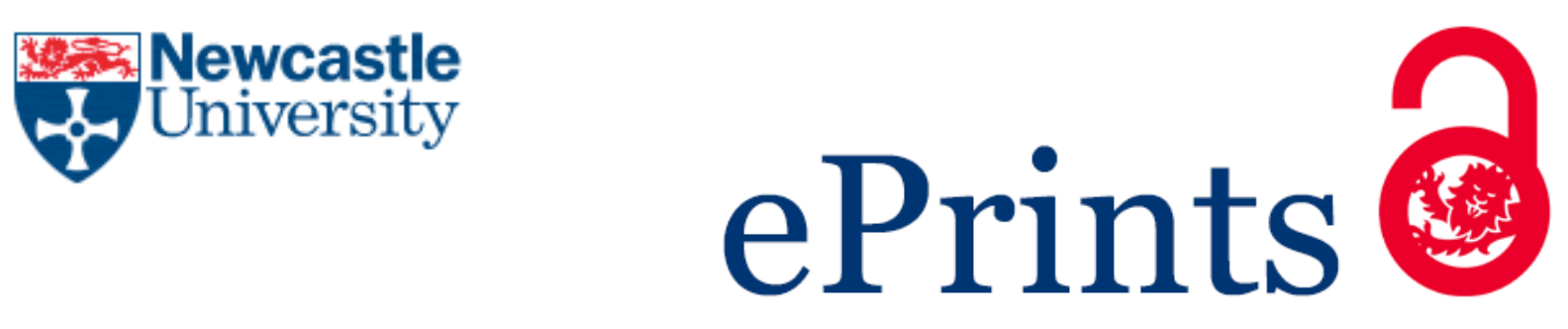

England RM, Hare JI, Barnes J, Wilson J, Smith A, Strittmatter N, Kemmitt PD, Waring MJ, Barry ST, Alexander C, Ashford MB.

Tumour regression and improved gastrointestinal tolerability from controlled release of $\mathrm{SN}-38$ from novel polyoxazoline-modified dendrimers. Journal of Controlled Release 2017, 247, 73-85.

\title{
Copyright:
}

(C) 2017. This manuscript version is made available under the CC-BY-NC-ND 4.0 license

DOI link to article:

http://dx.doi.org/10.1016/j.jconrel.2016.12.034

Date deposited:

$06 / 01 / 2017$

Embargo release date:

30 December 2017

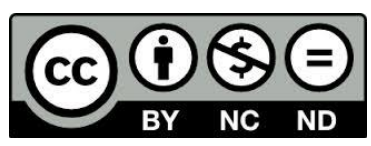

This work is licensed under a

Creative Commons Attribution-NonCommercial-NoDerivatives 4.0 International licence 


\section{Tumour regression and improved gastrointestinal tolerability from controlled release of SN-38 from novel polyoxazoline-modified dendrimers}

Richard M. England, ${ }^{a, 1, *}$ Jennifer I. Hare ${ }^{\mathrm{b}, 1, *}$ Jennifer Barnes, ${ }^{\mathrm{d}}$ Joanne Wilson, ${ }^{\mathrm{c}}$ Aaron

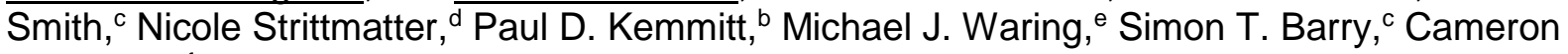
Alexander, ${ }^{f}$ and Marianne B. Ashford. ${ }^{a}$

a. AstraZeneca, Pharmaceutical Sciences, Innovative Medicines, Silk Court Business Park, Macclesfield, Cheshire, SK10 2NA, United Kingdom.

b. AstraZeneca, IMED Oncology, Alderley Park, Macclesfield, Cheshire, UK, SK10 4TG, United Kingdom.

c. AstraZeneca, IMED Oncology, Li Ka Shing Centre, CRUK Cambridge Institute, Cambridge, CB2 ORE, United Kingdom.

d. AstraZeneca, Pathological Sciences, Drug Safety and Metabolism, Cambridge, CB4 0WG, United Kingdom.

e. Northern Institute for Cancer Research, School of Chemistry, Bedson Building, Newcastle University, Newcastle upon Tyne, NE1 7RU, United Kingdom.

f. School of Pharmacy, University of Nottingham, Nottingham, NG7 2RD, United Kingdom.

${ }^{1}$ Authors contributed equally to this work.

*Corresponding author E-mail addresses: Richard.England@astrazeneca.com, Jennifer.Hare@ astrazeneca.com

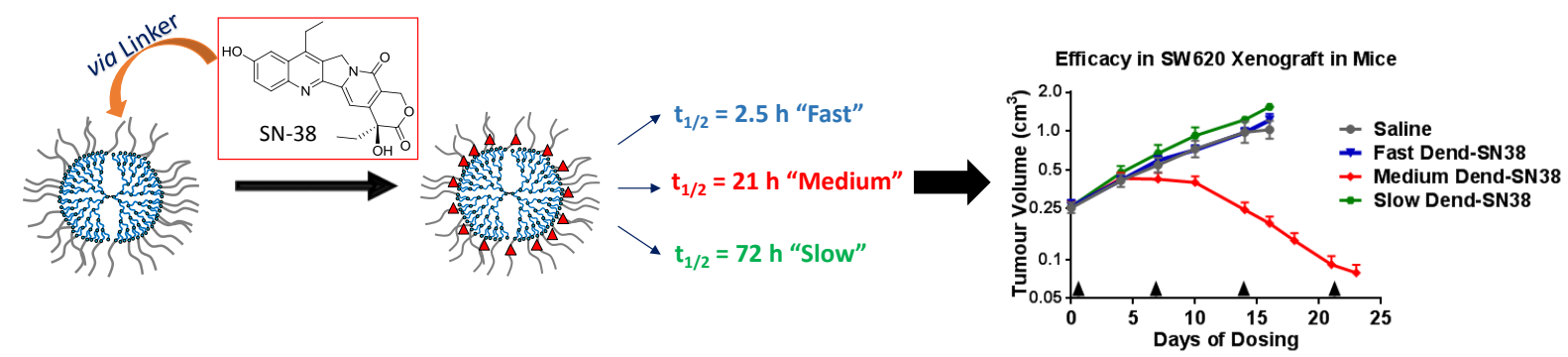

\section{Abstract}

Irinotecan is used clinically for the treatment of colorectal cancer; however, its utility is limited by its narrow therapeutic index. We describe the use of a generation 5 L-lysine dendrimer that has been part-modified with a polyoxazoline as a drug delivery vehicle for improving the therapeutic index of $\mathrm{SN}-38$, the active metabolite of irinotecan. By conjugating SN-38 to the dendrimer via different linker technologies we sought to vary the release rate of the drug to generate diverse pharmacokinetic profiles. Three conjugates with plasma release half-lives of $2.5 \mathrm{~h}, 21 \mathrm{~h}$, and $72 \mathrm{~h}$ were tested for efficacy and toxicity using a mouse SW620 xenograft model. In this model, the linker with a plasma release half-life of $21 \mathrm{~h}$ achieved sustained SN-38 exposure in blood, above the target concentration. Control over the release rate of the drug from the linker, combined with prolonged circulation of the dendrimer, enabled administration of an efficacious dose of SN-38, achieving significant regression of the SW620 tumours. The conjugates with 2.5 and $72 \mathrm{~h}$ release half-lives did not achieve an antitumour effect. Intraperitoneal dosing of the clinically used prodrug irinotecan produces high initial and local concentrations of $\mathrm{SN}-38$, which are associated with gastrointestinal toxicity. Administration of the $21 \mathrm{~h}$ release dendrimer conjugate did not produce a high initial $\mathrm{C}_{\max }$ of SN-38. Consequently, a marked reduction in gastrointestinal toxicity was observed relative to irinotecan treatment. Additional studies investigating the dose concentrations and dose scheduling showed that a weekly dosing schedule of $4 \mathrm{mg} \mathrm{SN}-38 / \mathrm{kg}$ was the most efficacious regimen. After 4 doses at weekly intervals, the survival period of the mice extended beyond 70 days following the final dose. These extensive studies have allowed us to identify a linker, dose and dosing regimen for SN-38 conjugated to polyoxazoline-modified dendrimer that maximised efficacy and minimised adverse side effects. 


\section{Keywords}

Nanomedicine; Irinotecan; SN-38; Dendrimer; Colorectal cancer; Drug delivery; Therapeutic index.

\section{Introduction}

One of the key considerations for cancer medicines remains establishing a therapeutic index [1], since targeting key cellular processes can induce significant toxicity, and therapeutic margins are typically narrow, or almost non-existent for some specific potent cytotoxic therapies.

Topoisomerases are ubiquitous enzymes that control DNA supercoiling and entanglements. They cleave the DNA backbone, releasing DNA supercoils and re-ligating the cleaved DNA. Topoisomerases are essential during the transcription and replication process, and topoisomerase inhibitors that cause single or double strand cleavage (type I or II, respectively) are among the most effective and most commonly used anticancer and antibacterial drugs [2]. Topotecan and irinotecan are topoisomerase I inhibitors routinely used in the clinic in a range of different cancers. They are water soluble semi-synthetic derivatives of the potent cytotoxic plant alkaloid camptothecin. However, serious adverse effects, including myelosuppression and diarrhoea, have limited their efficacy in the clinic.

In addition, irinotecan is a prodrug, which is hydrolysed to its more potent active metabolite, SN-38, by carboxylesterases in the liver and tumour cells. This conversion is often inefficient in humans, and leads to variability in SN-38 exposure [3]. Although SN-38 is 100- to 1000-fold more potent than irinotecan [3], its clinical use is limited by its poor water solubility and chemical instability of its pharmacologically active lactone ring at $\mathrm{pH}>6$. Alongside the narrow therapeutic index of irinotecan and $\mathrm{SN}-38$, these issues present further challenges for their use as anti-cancer therapeutics in the clinic.

In principle, one way to improve therapeutic index is to increase drug exposure in diseased tissue, without accumulation in other healthy tissues. Nanotechnology offers the possibility to achieve greater site specificity by changing the biodistribution of a drug. These drug delivery systems have been shown to increase drug concentration at tumour sites, relative to off-target tissues. This is often achieved by minimising the high initial drug concentrations in the plasma $\left(C_{\max }\right)$ and allowing tissue accumulation and retention via the enhanced permeability and retention (EPR) effect $[4,5]$. The rapidly developing field of nanomedicines covers a range of nano-scale constructs, such as liposomes, polymeric nanoparticles, polymeric micelles, various polymer conjugates and inorganic particles.

Several nanomedicine delivery strategies have been investigated to improve the therapeutic index of $\mathrm{SN}-38$ and camptothecin analogues, by reducing accumulation in normal tissues while increasing delivery to tumours. To date, $\mathrm{SN}-38$ and camptothecin analogues have been delivered using liposomes, polymeric nanoparticles, polymeric micelles and various polymer conjugates and antibody drug conjugates [6-12].

Onivyde $^{\mathrm{TM}}$ (Merrimack Pharmaceuticals), a liposomal irinotecan, has recently been approved for use in metastatic pancreatic cancer and is currently being used in Phase II trials in gastric cancer. Etirinotecan pegol (ONZEALD ${ }^{\mathrm{TM}}$, formerly NKTR-102; Nektar Therapeutics) is in advanced clinical development for ovarian, breast, colon, and lung cancers $[13,14]$. Both of these nano-formulations provide greater area under the curve (AUC) for SN-38 than does irinotecan treatment in pre-clinical tumours [14]. A camptothecin nanoparticle polymer conjugate, CRLX101 (Cerulean Pharma Inc.) is 
currently in clinical trials in a number of cancers. CRLX101 has demonstrated an extended circulation half-life and prolonged release of camptothecin in rat, dog, and human plasma [15], sustained tumour pharmacokinetics and inhibition of target [16], and evidence of localisation in tumour rather than healthy tissues in gastric cancer patients [17].

All of these systems have demonstrated positive results in pre-clinical models and are progressing in the clinic with promising activity. However, the ability to control the release of the payload from the nano-carrier has not been explored, precluding the possibility of fine-tuning the release rate to maximise the therapeutic index. The ability to explore the relationship between efficacy and toxicity across a range of release rates generates insight that drives biology-focussed nanomedicine design [18].

Dendrimer drug conjugates offer many advantages over other drug delivery systems, including tuneable drug release. Additional benefits of the dendrimer platform include: control of size during synthesis, near-monomodal molecular weight distributions, and reproducible synthetic sequences. Dendrimers are significantly smaller $(\sim 7-15 \mathrm{~nm})$ than polymeric nanoparticles prepared via other routes. Nanomedicine systems of similar sizes have been shown to extravasate to a greater extent and/or penetrate farther from the vasculature than do larger systems, which has been associated with improved efficacy [19-21]. In addition, dendrimers have large numbers of surface groups available for conjugation. These surface groups can be used for drug conjugation via different linker chemistries, without significantly impacting solubility, or to modify the outer layer of the dendrimer. This modification controls surface charge and provides a corona to prevent protein adsorption, thereby extending the circulation time of the dendrimer conjugate. PEGylation has been widely employed with polyamidoamine (PAMAM) [22-25] and poly(L-lysine) dendrimers [26-29] for surface modification. There is now significant diversity in the dendrimer-based nanomedicines being explored pre-clinically, including amphiphilic dendrimers forming nanomicelles [30], dendrimerassisted metal nanocomposite particles for CT/MR imaging [31], lactoferrin-containing dendriplexes [32], and doxorubicin-conjugated dendrimers for pulmonary delivery [33].

We have built on this strategy using a biodegradable fifth generation L-lysine dendrimer, partmodified with a polyoxazoline [34], to deliver the potent topoisomerase I inhibitor SN-38. Recognising the importance of controlled drug release in designing nanomedicines and optimising therapeutic index [35-40], we designed a range of linker chemistries to tune the release rate of SN38 , and explored the synthesis, characterisation and therapeutic application of three dendrimerSN38 (Dend-SN38) conjugates in vitro and in vivo.

\section{Materials and methods}

\section{Materials}

All reagents and solvents were purchased from Sigma-Aldrich and used as received with exception of SN-38 (TCl Europe N.V.), N,N'-Disuccinimidyl carbonate \& 2-chloro-4,6-dimethoxy-1,3,5-triazine (Chem-Impex International). Irinotecan was purchased from CarboSynth (UK).

\section{Methods}

HPLC-UV was performed on an Agilent 1100 fitted with an Atlantis dC18 $5 \mu \mathrm{m} 4.6 \times 150 \mathrm{~mm}$ column with an acetonitrile/water gradient $+1 \%$ TFA modifier. See Supporting Information Table S1 for HPLC-UV run parameters. The data were analysed using Thermo Scientific ${ }^{\mathrm{TM}}$ Atlas Chromatography Data System (CDS) software. GPC was performed on a Malvern TDA302 using a Tosoh Bioscience TSKgel GMPWxI column and an eluent of a 40: $10 \mathrm{mM} \mathrm{NaNO}_{3}: \mathrm{NaH}_{2} \mathrm{PO}_{4}+10 \% \mathrm{MeOH}$ in water. Samples were made to $2 \mathrm{mg} / \mathrm{ml}$ in the eluent. The system calibration was performed using a single poly(ethylene oxide) standard (16 $\left.100 \mathrm{~g} \mathrm{~mol}^{-1}\right)$ and absolute molecular weights determined using the 
refractive index and light scattering signals. Dynamic light scattering was performed on a Malvern Zetasizer $^{\circledast}$ Nano ZS instrument with back scattering detector $\left(173^{\circ}, 633 \mathrm{~nm}\right.$ laser wavelength). The dispersant RI and viscosity were assumed to be that of water ( $n=1.59$ and $\eta=0.888 \mathrm{mPa} \cdot \mathrm{s})$. The sample RI was 1.59 and the temperature was set at $25^{\circ} \mathrm{C}$. The hydrodynamic diameter (DH) was reported as the volume-weighted average after a minimum of twelve measurements per sample and was calculated by the software. Samples were made to concentrations of $5 \mathrm{mg} / \mathrm{ml}$ in PBS at pH 7.4 and were filtered using a $0.2 \mu \mathrm{m}$ syringe filter prior to measurement. Data was obtained using Malvern Zetasizer software version 6.21J.

4-(4,6-Dimethoxy-1,3,5-triazin-2-yl)-4-methylmorpholinium tetrafluoroborate (DMTMM.BF ${ }_{4}$ ) was synthesised according to methods reported previously [41].

G5-PLL[PMOx $]_{x}\left[\mathrm{NH}_{2}\right]_{\mathrm{y}}$. This product was synthesised according to methods previously described [34]. $\mathrm{M}_{\mathrm{n}}=75.7 \mathrm{~kg} / \mathrm{mol}, \mathrm{PDI}=1.17$ from triple detection size exclusion chromatography.

G5-PLL[PMOx] $]_{x}[\text { Azide] }]_{y}$ G5-PLL[PMOx][NH $\left.{ }_{2}\right](750 \mathrm{mg}, 9.78 \mu \mathrm{mol})$ was dissolved in anhydrous DMF (5 $\mathrm{mL}$ ) at $45^{\circ} \mathrm{C}$. The solution was cooled to room temperature. A pre-mixed solution of 2-azidoacetic acid (93 $\mu \mathrm{L}, 1.25 \mathrm{mmol}), \mathrm{N}$-(3-Dimethylaminopropyl)- $\mathrm{N}^{\prime}$-ethylcarbodiimide hydrochloride (EDC) (240 $\mathrm{mg}, 1.25 \mathrm{mmol}$ ) and 4-(Dimethylamino)pyridine (DMAP) $(15 \mathrm{mg}, 0.12 \mathrm{mmol})$ in anhydrous DMF (5 $\mathrm{mL}$ ) was added to the polymer solution and stirred overnight at room temperature. The reaction mixture was added drop-wise to rapidly stirring diethyl ether $(200 \mathrm{~mL})$ to form a white precipitate which was collected by filtration and dried under vacuum for 2 hours at room temperature. The solid was then taken up in deionised water $(50 \mathrm{~mL})$, passed through a $0.45 \mu \mathrm{m}$ nylon filter cup and purified by VivaFlow ${ }^{\circledR}$ cassette in deionised water $(30 \mathrm{kDa} \mathrm{MWCO})$. The title compound was obtained as a white solid after freeze-drying ( $675 \mathrm{mg}, 87 \%)$. $1 \mathrm{H} \mathrm{NMR}\left(400 \mathrm{MHz}, \mathrm{D}_{2} \mathrm{O}\right) 1.12-1.86$ (br, $367 \mathrm{H}), 1.89-2.3(\mathrm{br}, 1500 \mathrm{H}), 3.19(\mathrm{br}, 136 \mathrm{H}), 3.56(\mathrm{br}, 1940 \mathrm{H}), 3.92(\mathrm{br}, 111 \mathrm{H}), 4.04-4.44(\mathrm{br}$, $130 \mathrm{H})$.

6-amino-N-(prop-2-ynyl)hexanamide. Boc-6-aminohexanoic acid (1.0 g, $4.32 \mathrm{mmol}$ ) was dissolved in anhydrous DCM $(25 \mathrm{~mL})$ in a reaction tube purged with nitrogen. EDC $(1.34 \mathrm{~g}, 8.64 \mathrm{mmol})$ was added as a solid and stirred until dissolved. DMAP $(0.1 \mathrm{~g}, 8.65 \mathrm{mmol})$ was added followed by propargylamine $(0.831 \mathrm{~mL}, 12.97 \mathrm{mmol})$ dropwise via Gilson pipette. The reaction was stirred overnight at room temperature before diluting with further DCM $(25 \mathrm{~mL})$ and washing with $0.1 \mathrm{M} \mathrm{HCl}$ $(2 \times 25 \mathrm{~mL})$, saturated $\mathrm{NaHCO}_{3}(2 \times 25 \mathrm{~mL})$ and saturated brine $(25 \mathrm{~mL})$. The organic phase was dried over magnesium sulphate, filtered and evaporated under vacuum to obtain the title compound as a white solid (0.632 g, 55 \%).1H NMR (CDCl3, $400 \mathrm{MHz}): \delta=1.36(\mathrm{~m}, 2 \mathrm{H}), \delta=1.44(\mathrm{~s}, 9 \mathrm{H}), \delta=1.50(\mathrm{~m}$, $2 \mathrm{H}), \delta=1.67(\mathrm{~m}, 2 \mathrm{H}), \delta=3.11(\mathrm{q}, 2 \mathrm{H}), \delta=4.05(\mathrm{dd}, 2 \mathrm{H}), \delta=4.46-4.61(\mathrm{~b}, 1 \mathrm{H}), \delta=5.56-5.69(\mathrm{~b}, 1 \mathrm{H})$.

6-amino-N-(prop-2-yn-1-yl)hexanamide. HCl. 6-amino-N-(prop-2-ynyl)hexanamide $\left(\begin{array}{lll}0.60 & \text { g, } 2.24\end{array}\right.$ $\mathrm{mmol}$ ) was dissolved in methanol $(5 \mathrm{~mL})$ in a round bottom flask fitted with a gas outlet. $\mathrm{HCl}(1.68$ $\mathrm{mL}, 4 \mathrm{M}$ in dioxane) was added drop-wise and the reaction was stirred at room temperature for 6 hours. The solvents were evaporated under vacuum and the residue was washed with DCM $(25 \mathrm{~mL})$. The remaining solid was dried under vacuum at room temperature overnight to give the title compound as a pale brown solid (0.39 g, $85 \%)$. $1 \mathrm{H} \mathrm{NMR} \mathrm{(400MHz,} \mathrm{d-DMSO)} 1.22-1.37(2 \mathrm{H}, \mathrm{m})$, $1.49(2 \mathrm{H}, \mathrm{m}), 1.53-1.62(2 \mathrm{H}, \mathrm{m}), 2.09(2 \mathrm{H}, \mathrm{t}), 2.64-2.82(2 \mathrm{H}, \mathrm{m}), 3.06(1 \mathrm{H}, \mathrm{t}), 3.83(2 \mathrm{H}, \mathrm{dd})$.

tert-butyl methyl(3-oxo-3-(prop-2-yn-1-ylamino)propyl)carbamate. This compound was synthesized as above using boc-sarcosine $(1.0 \mathrm{~g}, 5.29 \mathrm{mmol})$. The title compound was obtained as a white solid (0.59 g, $49 \%$ ). $\left.1 \mathrm{H} \mathrm{NMR} \mathrm{(} \mathrm{CDCl}_{3}, 400 \mathrm{MHz}\right): \delta=1.48(\mathrm{~s}, 9 \mathrm{H}), \delta=2.23(\mathrm{t}, 1 \mathrm{H}), \delta=1.48(\mathrm{~s}, 3 \mathrm{H})$, $\delta=3.86(\mathrm{~s}, 2 \mathrm{H}), \delta=4.07(\mathrm{dd}, 2 \mathrm{H})$. 
2-(methylamino)-N-(prop-2-ynyl)acetamide.HCl. This compound was synthesised according to the above method. The title compound was obtained as a pale brown solid ( $0.38 \mathrm{~g}, 72 \%)$. $1 \mathrm{H}$ NMR (d6acetone, $400 \mathrm{MHz}): \delta=2.87(\mathrm{~s}, 3 \mathrm{H}), \delta=3.66(\mathrm{~s}, 1 \mathrm{H}), \delta=3.98(\mathrm{~m}, 4 \mathrm{H})$.

SN-38 6-oxo-6-(prop-2-ynylamino)hexylcarbamate (1a). SN-38 (75 mg, $0.19 \mathrm{mmol}$ ) was dissolved in a mixture of THF $(6 \mathrm{~mL})$ and acetonitrile $(6 \mathrm{~mL})$ with $\mathrm{N}, \mathrm{N}$-Diisopropylethylamine (DIPEA) $(0.100 \mathrm{~mL}$, $0.57 \mathrm{mmol})$ in a $10 \mathrm{~mL}$ reaction vial purged with nitrogen. bis(2,5-dioxopyrrolidin-1-yl) carbonate $(196 \mathrm{mg}, 0.76 \mathrm{mmol})$ was added directly as a solid. The reaction was monitored by HPLC and when full conversion of the SN-38 was observed ( $\sim 30 \mathrm{~min}$ ) the reaction mixture was diluted with EtOAc (25 $\mathrm{mL})$, and washed with $0.1 \mathrm{M} \mathrm{HCl}(2 \times 10 \mathrm{~mL})$ and saturated brine $(2 \times 10 \mathrm{~mL})$. The organic layer was dried over $\mathrm{MgSO}_{4}$, filtered and evaporated to afford the intermediate. The intermediate was dissolved in DCM $(15 \mathrm{~mL})$ before DMAP $(9.34 \mathrm{mg}, 0.08 \mathrm{mmol})$, and 6-Amino-N-(prop-2-yn-1$\mathrm{yl}$ )hexanamide. $\mathrm{HCl}(58.7 \mathrm{mg}, 0.29 \mathrm{mmol})$ dissolved in DMF $(2 \mathrm{~mL}$ ) were added followed by DIPEA (33 $\mu \mathrm{L}, 0.19 \mathrm{mmol})$. The reaction mixture was stirred at room temperature under nitrogen until the reaction had gone to completion (measured by LCMS, $\sim 10 \mathrm{~min}$ ). The solvent was evaporated and the crude product was purified by flash silica chromatography with an elution gradient of $10-80 \% 3: 1$ EtOAc: EtOH in heptane. The title compound was obtained as a pale yellow solid after evaporation. (85 mg, 76 \%). 1H NMR (400 MHz, CDCl $) 1.04(4 \mathrm{H}, \mathrm{t}), 1.31-1.49(8 \mathrm{H}, \mathrm{m}), 1.6-1.69(3 \mathrm{H}, \mathrm{m}), 1.72$ $(3 \mathrm{H}, \mathrm{dd}), 1.79-2(3 \mathrm{H}, \mathrm{m}), 2.15-2.29(4 \mathrm{H}, \mathrm{m}), 2.51-2.63(1 \mathrm{H}, \mathrm{m}), 2.74(2 \mathrm{H}, \mathrm{s}), 2.88(2 \mathrm{H}, \mathrm{d}), 2.95$ $(2 \mathrm{H}, \mathrm{s}), 3.16(2 \mathrm{H}, \mathrm{q}), 3.34(2 \mathrm{H}, \mathrm{dt}), 4.06(3 \mathrm{H}, \mathrm{dd}), 5.26(3 \mathrm{H}, \mathrm{s}), 5.28-5.37(2 \mathrm{H}, \mathrm{m}), 5.75(1 \mathrm{H}, \mathrm{d}), 7.60$ $(1 \mathrm{H}, \mathrm{dd}), 7.63(1 \mathrm{H}, \mathrm{s}), 7.88(1 \mathrm{H}, \mathrm{d}), 8.21(1 \mathrm{H}, \mathrm{d})$.

SN-38 methyl(2-oxo-2-(prop-2-ynylamino)ethyl)carbamate (1c). This compound was synthesized as for 1a using 1a using 2-(methylamino)- $\mathrm{N}$-(prop-2-ynyl)acetamide. $\mathrm{HCl}$. The title compound was obtained as a pale yellow solid (76 mg, $73 \%$ ). 1H NMR (400 MHz, $\left.\mathrm{CDCl}_{3}\right) 1.04(3 \mathrm{H}, \mathrm{t}), 1.42(3 \mathrm{H}, \mathrm{dt})$, $1.54(3 \mathrm{H}, \mathrm{s}), 1.75-2(2 \mathrm{H}, \mathrm{m}), 2.26(1 \mathrm{H}, \mathrm{s}), 3.15(3 \mathrm{H}, \mathrm{d}), 3.30(2 \mathrm{H}, \mathrm{s}), 3.49(1 \mathrm{H}, \mathrm{s}), 3.76(1 \mathrm{H}, \mathrm{d}), 3.96-$ $4.28(4 \mathrm{H}, \mathrm{m}), 5.24(2 \mathrm{H}, \mathrm{s}), 5.27-5.33(1 \mathrm{H}, \mathrm{m}), 5.75(1 \mathrm{H}, \mathrm{dd}), 7.61(2 \mathrm{H}, \mathrm{s}), 7.8-7.92(1 \mathrm{H}, \mathrm{d}), 8.22(1 \mathrm{H}$, d).

SN-38 hex-5-ynoate (1b). Hex-5-ynoic acid $(23 \mu \mathrm{L}, 0.21 \mathrm{mmol})$ was dissolved in anhydrous DMF (7 $\mathrm{mL}$ ) in a nitrogen-purged reaction vial. EDC $(73.3 \mathrm{mg}, 0.38 \mathrm{mmol})$ was added as a solid, followed by DMAP ( $46.7 \mathrm{mg}, 0.38 \mathrm{mmol}$ ) and the mixture stirred for 5 minutes. 7-Ethyl-10-hydroxycamptothecin (75 $\mathrm{mg}, 0.19 \mathrm{mmol}$ ) was added as a solid and the reaction stirred overnight. The reaction mixture was diluted with ethyl acetate $(50 \mathrm{~mL})$, and washed with $0.1 \mathrm{M} \mathrm{HCl}(2 \times 20 \mathrm{~mL})$, and saturated brine $(2 \times 20 \mathrm{~mL})$. The organic layer was dried over $\mathrm{MgSO}_{4}$, filtered and evaporated to afford the crude product. The crude was purified by flash silica chromatography with a 20-70\% elution gradient of 3:1 EtOAc: EtOH in heptane. The title compound was obtained as a pale yellow solid after evaporation of the solvents (69.2 mg, 74.4\%). 1H NMR (400 MHz, CDCl $) 1.04(3 \mathrm{H}, \mathrm{t}), 1.40(3 \mathrm{H}, \mathrm{t}), 1.90(2 \mathrm{H}, \mathrm{ddt})$, $1.99-2.11(3 \mathrm{H}, \mathrm{m}), 2.41(2 \mathrm{H}, \mathrm{td}), 2.83(2 \mathrm{H}, \mathrm{t}), 3.15(2 \mathrm{H}, \mathrm{q}), 5.25(2 \mathrm{H}, \mathrm{s}), 5.27-5.33(1 \mathrm{H}, \mathrm{m}), 5.74(1 \mathrm{H}$, d), $7.55(1 \mathrm{H}, \mathrm{dd}), 7.64(1 \mathrm{H}, \mathrm{s}), 7.83(1 \mathrm{H}, \mathrm{d}), 8.23(1 \mathrm{H}, \mathrm{d})$.

2-(4-(4-oxo-4-SN38 butyl)-1H-1,2,3-triazol-1-yl)acetic acid (16'). The reaction for $1 \mathrm{~b}$ was repeated starting with $300 \mathrm{mg}$ of $\mathrm{SN}-38$ to yield $294 \mathrm{mg}(0.60 \mathrm{mmol})$ of product $(79.0 \%)$. This product was dissolved in anhydrous DMF $(10 \mathrm{~mL})$ in a nitrogen purged reaction vial. 2-azidoacetic acid $(227 \mu \mathrm{L}$, $3.02 \mathrm{mmol}$ ) was added via Gilson pipette followed by copper(II) sulphate pentahydrate (15 $\mathrm{mg}, 0.06$ $\mathrm{mmol}$ ) and sodium ascorbate $(24 \mathrm{mg}, 0.12 \mathrm{mmol})$. After 10 minutes the reaction had gone to completion as observed by LCMS and the reaction mixture was diluted with ethyl acetate $(100 \mathrm{~mL})$ and was washed with $0.1 \mathrm{M} \mathrm{HCl}(3 \times 25 \mathrm{~mL})$ and saturated brine $(3 \times 25 \mathrm{~mL})$. The organic phase was dried over magnesium sulphate and dried under vacuum. The crude was purified by flash silica chromatography with an elution gradient of 10-80\% 3:1 EtOAc: EtOH $+10 \% \mathrm{AcOH}$ in heptane. The title compound was obtained as a pale yellow solid after evaporation of the solvents ( $278 \mathrm{mg}, 78 \%$ ). 
1H NMR (400 MHz, d-DMSO) $0.90(3 \mathrm{H}, \mathrm{q}), 1.31(3 \mathrm{H}, \mathrm{t}), 1.89(2 \mathrm{H}, \mathrm{tq}), 2.06(2 \mathrm{H}, \mathrm{p}), 2.71-2.85(4 \mathrm{H}, \mathrm{m})$, $3.20(3 \mathrm{H}, \mathrm{q}), 5.19(2 \mathrm{H}, \mathrm{s}), 5.35(2 \mathrm{H}, \mathrm{s}), 5.44(2 \mathrm{H}, \mathrm{s}), 6.48(1 \mathrm{H}, \mathrm{s}), 7.34(1 \mathrm{H}, \mathrm{s}), 7.68(1 \mathrm{H}, \mathrm{dd}), 7.92(1 \mathrm{H}$, s), $8.03(1 \mathrm{H}, \mathrm{d}), 8.22(1 \mathrm{H}, \mathrm{d})$.

G5-PLL[PMOx $]_{x}[1 \text { [a]y (2a). G5-PLL[PMOx }]_{x}[\text { Azide }]_{y}(150 \mathrm{mg}, 1.89 \mu \mathrm{mol})$ was dissolved in water $(2 \mathrm{~mL})$ in a nitrogen purged reaction vial. $1 \mathrm{a}(44 \mathrm{mg}, 0.08 \mathrm{mmol})$ dissolved in methanol $(6 \mathrm{ml})$ was added followed by copper(II) sulphate pentahydrate $(2.4 \mathrm{mg}, 9.45 \mu \mathrm{mol})$ and sodium ascorbate $(3.7 \mathrm{mg}$, $0.02 \mathrm{mmol}$ ). The reaction mixture was stirred for 1 hour before reducing the volume of the reaction mixture by half under vacuum. The product was purified by size exclusion column (LH2O) in methanol, collecting $0.5 \mathrm{~mL}$ fractions which were evaporated, taken up in deionised water and freeze-dried. The polymer fractions were collated to give the title compound as a pale yellow solid (184 mg, 96 \%). D.L. = 8.1 wt. \%. 1H NMR (400 MHz, D $\left.{ }_{2} \mathrm{O}\right) 1.12-1.86(\mathrm{br}, 367 \mathrm{H}), 1.89-2.3(\mathrm{br}$, $1500 \mathrm{H}), 3.19$ (br, 136H), 3.56 (br, 1940H), 3.92 (br, 111H), $4.04-4.44$ (br, 130H), 6.92-8.04 (br, 98H, $\mathrm{SN}-38)$.

G5-PLL[PMOx $]_{x}[\mathbf{1 b}]_{y}$ (2b). This product was synthesised as for $\mathbf{2 a}$ to yield a pale yellow solid (125 $\mathrm{mg}, 69$ \%). D.L. $=8.5$ wt.\%. $1 \mathrm{H}$ NMR $\left(400 \mathrm{MHz}, \mathrm{D}_{2} \mathrm{O}\right) 1.12-1.86(\mathrm{br}, 367 \mathrm{H}), 1.89-2.3(\mathrm{br}, 1500 \mathrm{H})$, $3.19(\mathrm{br}, 136 \mathrm{H}), 3.56(\mathrm{br}, 1940 \mathrm{H}), 3.92(\mathrm{br}, 111 \mathrm{H}), 4.04-4.44(\mathrm{br}, 130 \mathrm{H}), 6.92-8.04(\mathrm{br}, 101 \mathrm{H}, \mathrm{SN}-38)$.

G5-PLL[PMOx $]_{x}[\mathbf{1 c}]_{y} \mathbf{( 2 c )}$. This product was synthesised as for $\mathbf{2 a}$ to yield a pale yellow solid $(133 \mathrm{mg}$, 73 \%). D.L. = 8.3 wt. \%. $1 \mathrm{H} \mathrm{NMR}\left(400 \mathrm{MHz}, \mathrm{D}_{2} \mathrm{O}\right) 1.12-1.86(\mathrm{br}, 367 \mathrm{H}), 1.89-2.3(\mathrm{br}, 1500 \mathrm{H}), 3.19$ (br, 136H), 3.56 (br, 1940H), $3.92(b r, 111 \mathrm{H}), 4.04-4.44$ (br, 130H), 6.92-8.04 (br, 103H, SN-38).

G5-PLL[PMOx $]_{x}\left[\mathbf{1 b}^{\prime}\right]_{y} \cdot\left(\mathbf{2 b}^{\prime}\right)$ Product 16' $(250 \mathrm{mg}, 0.43 \mathrm{mmol})$ was dissolved in anhydrous DMF $(10 \mathrm{~mL})$ and $\mathrm{DMTMM}_{\mathrm{BF}}(225 \mathrm{mg}, 0.69 \mathrm{mmol})$ was added. The reaction mixture was stirred for 10 minutes at room temperature. G5-PLL[PMOx $]_{x}\left[\mathrm{NH}_{2}\right]_{y}(820 \mathrm{mg}, 10.71 \mu \mathrm{mol})$ and triethylamine $(48 \mu \mathrm{L}$, $0.34 \mathrm{mmol})$ dissolved in anhydrous DMF $(5 \mathrm{~mL})$ were added and the reaction mixture stirred under nitrogen at room temperature for 5 hours (the reaction progress was regularly followed by LC-MS at $254 \mathrm{~nm})$. The reaction mixture was diluted with ethyl acetate $(15 \mathrm{~mL})$ and then added dropwise to rapidly stirring diethyl ether $(500 \mathrm{~mL})$ to form a pale yellow precipitate. The precipitate was collected and dried under vacuum at room temperature for 1 hour. The solid was taken up in $50 \mathrm{~mL}$ of a 2:1:1 mixture of $0.1 \mathrm{M} \mathrm{KH}_{2} \mathrm{PO}_{4}$ buffer $(\mathrm{pH} 3)$, DI water and ethanol before purifying by VivaFlow (30 kDa MWCO) for several cycles, before changing over to $100 \%$ deionised water when the solution was absent of impurities and free drug as detected by LC-MS. The title compound was obtained as a pale yellow solid after freeze-drying ( $850 \mathrm{mg}, 84 \%)$. D.L. = 7.7 wt. \%. $\left.1 \mathrm{H} \mathrm{NMR} \mathrm{(400} \mathrm{MHz,} \mathrm{D}_{2} \mathrm{O}\right) 1.12-1.86$ (br, 367H), $1.89-2.3(\mathrm{br}, 1500 \mathrm{H}), 3.19(\mathrm{br}, 136 \mathrm{H}), 3.56$ (br, 1940H), $3.92(\mathrm{br}, 111 \mathrm{H}), 4.04-4.44(\mathrm{br}$, $130 \mathrm{H}), 6.92-8.04(\mathrm{br}, 94 \mathrm{H}, \mathrm{SN}-38)$.

\section{Compound formulation}

For i.p. dosing, irinotecan was formulated in 7.5\% DMSO + 92.5\% water for injection (v/v); for i.v. dosing, irinotecan was formulated in $2.5 \%$ DMSO $+97.5 \%$ water for injection $(\mathrm{v} / \mathrm{v})$ and sterilefiltered. SN-38 was dissolved in saline according to the following method: SN-38 was dissolved in $\mathrm{NaOH}$ solution (2M) (3.5 $\mu \mathrm{L}$ per $1 \mathrm{mg} \mathrm{SN}-38)$. The bright yellow solution was diluted with the required volume of saline and then $\mathrm{HCl}(2 \mathrm{M})(1 \mu \mathrm{L}$ for every $1 \mathrm{mg}$ of $\mathrm{SN}-38$ used) was added to ensure a stable, near-neutral solution was achieved. Dend-SN38 and unloaded dendrimer were hydrated in saline and sterile-filtered before injection.

\section{Dend-SN38 free drug loading}

An accurately weighed quantity of Dend-SN38 (1-2 mg) was weighed directly into a HPLC vial and dissolved in $1 \mathrm{~mL}$ of a 2:1 Methanol: $\mathrm{KH}_{2} \mathrm{PO}_{4}(0.1 \mathrm{M})$ mixture. The samples were measured by HPLC- 
UV immediately after dissolution (to minimise any release of $\mathrm{SN}-38$ ) and the free drug content was reported as a weight percentage from an average of 2 runs per sample.

\section{Dend-SN38 total drug loading}

Full release of $\mathrm{SN}-38$ from the dendrimer was achieved by dissolving an accurate quantity of DendSN38 (1-2 mg) in sodium hydroxide solution $(0.2 \mathrm{M}, 1 \mathrm{~mL})$ in a sealed HPLC vial and leaving at room temperature overnight (whilst prior hydrolysis studies having shown full release under these conditions in approximately $2 \mathrm{~h}$ (data not shown)). The drug loading was measured by HPLC-UV (254 $\mathrm{nm}), 1 \%$ ammonia in place of TFA) against a 6 point calibration curve for the ring-open (carboxylate) form of SN-38 dissolved in sodium hydroxide solution $(0.2 \mathrm{M})$. The total drug loading was reported as a weight percentage from an average of 2 runs per sample.

\section{Dend-SN38 in vitro release rates}

Dend-SN38 conjugates (2a-c) were weighed into HPLC vials (2 vials of $1.5 \mathrm{mg}$ per sample) and Wistar rat plasma $(500 \mu \mathrm{L})$ was added and gently mixed briefly until the conjugates had dissolved. Rat plasma was utilised to ensure that a sufficient volume for all experiments could be obtained in a single batch to eliminate batch-to-batch variation. The vials were sealed and incubated at $37^{\circ} \mathrm{C} .25$ $\mu \mathrm{L}$ aliquots were taken at time points $0.25 \mathrm{~h}, 0.5 \mathrm{~h}, 1 \mathrm{~h}, 2 \mathrm{~h}, 4 \mathrm{~h}, 8 \mathrm{~h}, 24 \mathrm{~h}, 48 \mathrm{~h}, 72 \mathrm{~h}$ and $96 \mathrm{~h}$. The samples were added directly to a Mini-UniPrep filter vial together with $300 \mu \mathrm{L} 10 \%$ AcOH in ACN. The sample was agitated for 2 minutes before filtering. $200 \mu \mathrm{L}$ of the filtered solution was added to a separate HPLC vial with $300 \mu \mathrm{L}$ of a 2:1 methanol: $\mathrm{KH}_{2} \mathrm{PO}_{4}(0.1 \mathrm{M})$ mixture and agitated before immediately measuring the released SN-38 content by HPLC-UV $(265 \mathrm{~nm})$. Full release of the SN-38 was measured by removing $25 \mu \mathrm{L}$ of the incubated plasma and adding $5 \mu \mathrm{L}$ of $2 \mathrm{M} \mathrm{NaOH}$ and then incubating at $37^{\circ} \mathrm{C}$ overnight in a sealed 96 -well plate. The plate was cooled over an ice bath and then the samples were neutralised by addition of $5 \mu \mathrm{L}$ of $2 \mathrm{M} \mathrm{HCl}$ and repeating the same steps as above accounting for the difference in volume when calculating the released SN-38. Release measurements in PBS were made similarly, except that $25 \mu \mathrm{L}$ aliquots were added directly to a HPLC vial with $300 \mu \mathrm{L}$ of a 2:1 methanol: $\mathrm{KH}_{2} \mathrm{PO}_{4}(0.1 \mathrm{M})$ mixture and measured directly by HPLC-UV.

\section{Animal models}

All animal studies were conducted in accordance with UK Home Office legislation, the Animal Scientific Procedures Act 1986, and the AstraZeneca Global Bioethics policy. All experimental work is outlined in project license 40/3483, which has gone through the AstraZeneca Ethical Review Process. Female nude (Hsd: Athymic Nude-Foxn1 nu) mice were purchased from Harlan Laboratories (now Envigo; UK). All mice weighed more than $18 \mathrm{~g}$ at the time of the first procedure. For studies in SW620 tumour-bearing mice, $1 \times 10^{6}$ cells in 50\% Matrigel were implanted subcutaneously onto the left flank of mice. Tumour growth was monitored twice weekly using intersecting calliper measurements; tumour volume was calculated from $3.14 *$ length*width ${ }^{2} / 6000$, where length is the longer dimension. Bodyweights were recorded at the time of tumour measurement, and daily if weight loss exceeded $8 \%$. Mice were randomised based on tumour volume to ensure an equal volume distribution across groups.

\section{Dend-SN38 pharmacokinetics}

To determine the plasma SN-38 concentrations achieved by the Dend-SN38 conjugates with different release rates, naive female nude mice ( $n=2$ /group) were injected intravenously with a single dose of slow, medium or fast release Dend-SN38 at $4 \mathrm{mg} / \mathrm{kg}$. Live bleeds were collected at various time points post-dose for determination of concentrations of free and bound $\mathrm{SN}-38$ via UPLC-MS/MS (conditions in Supporting Information Tables S2 and S3) against an SN-38 calibration curve (11 point standard calibration curve (1-10000 nM) prepared in DMSO and spiked into blank plasma). Briefly, $20 \mu \mathrm{L}$ of blood was collected from the tail vein using capillary tubes. Blood was diluted with $80 \mu \mathrm{L}$ of PBS and centrifuged at $13,000 \mathrm{rpm}$ for $5 \mathrm{~min}$ at $4^{\circ} \mathrm{C}$. The supernatant was 
collected and stored at $-80^{\circ} \mathrm{C}$ until analysis. At the time of analysis, the samples were defrosted over ice and two separate aliquots of $30 \mu \mathrm{L}$ were taken from each sample for liberated and total SN-38 concentrations. For liberated SN-38, $120 \mu \mathrm{L}$ of methanol/acetonitrile $(50 / 50)+1 \%$ acetic acid was added to the first aliquot to precipitate protein and stabilise any residual dendrimer-bound SN-38. The precipitate was agitated for 45 seconds before being filtered using a Mini-UniPrep Syringeless Filter $(0.45 \mu \mathrm{m}) .50 \mu \mathrm{L}$ of the filtrate was transferred to a deep 96-well plate and diluted with deionised water $(300 \mu \mathrm{L})$ and frozen at $-80^{\circ} \mathrm{C}$ prior to analysis. For the second aliquot where total SN38 levels were desired, the sample was placed into a 96 -well plate and $5 \mu \mathrm{L}$ of sodium hydroxide ( 2 $\mathrm{M})$ was added. The plate was sealed with adhesive 96 -well sealing tape and incubated at $40^{\circ} \mathrm{C}$ for 2 hours and was then placed on to an ice bath for 5 minutes before removing the sealing tape. $5 \mu \mathrm{L}$ of $\mathrm{HCl}(2 \mathrm{M})$ was added and the well contents were transferred to a Mini-UniPrep Syringeless Filter $(0.45 \mu \mathrm{m})$ followed by $110 \mu \mathrm{L}$ of acetonitrile/methanol $(50 / 50)+1 \%$ acetic acid and the same procedure for filtration of protein and transfer to deep 96-well plate was followed as for the liberated levels of SN-38. Whilst some of the intact dendrimer was removed by the acetonitrile protein precipitation, additional steps to prevent post-workup release form any intact dendrimer was minimised by addition of $\mathrm{KH}_{2} \mathrm{PO}_{4}$ buffer. Samples were measured immediately after workup or frozen at $-80^{\circ} \mathrm{C}$ until measurements could be made.

\section{SN-38 pharmacokinetics}

To characterise the plasma pharmacokinetics of SN-38 (carboxylate form), SW620 tumour-bearing mice $(n=5)$ were injected intravenously with a single dose of SN-38 at $2 \mathrm{mg} / \mathrm{kg}$. Live bleeds were collected at various time points post-dose for determination of SN-38 concentrations via UPLCMS/MS. The same procedure for sample preparation was used as for the Dend-SN38 pharmacokinetics above.

\section{Analysis of $\mathrm{SN}-38$ concentration in tumours}

Tumours were weighed and put into FastPrep Lysing Matrix A Tubes (MP Biomedicals UK). Three times the volume of water per tumour weight was added to the tumour for homogenisation. The samples were homogenised using a FastPrep-24 ${ }^{\mathrm{TM}}$ machine (MP Biomedicals UK) at $6 \mathrm{~m} / \mathrm{s}$ for 45 seconds. The cycle was repeated twice to gain complete homogenisation. Control tissue from undosed animals was homogenised as above and spiked with an 11 point standard calibration curve (1-10000 nM SN-38) prepared in DMSO. Tissue homogenates $(25 \mu \mathrm{L})$ were precipitated with acetonitrile $(100 \mu \mathrm{l})$ containing internal standard, followed by centrifugation at $4500 \mathrm{rpm}$ for 10 minutes. The supernatant $(50 \mu \mathrm{l})$ was then diluted in $300 \mu \mathrm{l}$ water and analysed via UPLC-MS/MS.

\section{Effect of Dend-SN38 release rate on anti-tumour efficacy}

To investigate the effect of Dend-SN38 release rate on anti-tumour activity and therapeutic index, an efficacy study was completed in mice bearing SW620 tumours. Animals were randomised for dosing when the average tumour volume reached $\sim 0.2 \mathrm{~cm}^{3}$. Mice $(\mathrm{n}=8-10 \mathrm{mice} / \mathrm{group})$ were dosed once weekly with saline (i.v.), irinotecan at $25 \mathrm{mg} / \mathrm{kg}$ (i.v.), irinotecan at $50 \mathrm{mg} / \mathrm{kg}$ (i.p.), unloaded dendrimer at $50 \mathrm{mg}$ polymer/kg (i.v.), or slow, medium or fast release Dend-SN38 conjugates at 4 $\mathrm{mg} \mathrm{SN}-38 / \mathrm{kg}$ (i.v.). A dose of $4 \mathrm{mg} \mathrm{SN}-38 / \mathrm{kg}$ required administration of $50 \mathrm{mg}$ Dend-SN38/kg, equalling $\sim 8 \%$ drug loading. Unless specified otherwise, the reported dose for the dendrimer conjugates is the dose of SN-38, not the polymer dose. Mice treated with irinotecan or medium release Dend-SN38 received 4 doses, while all other groups received 3 doses before tumour burden necessitated euthanasia as defined in the Project Licence. At $24 \mathrm{~h}$ after the final dose, mice were euthanised and the gastrointestinal tract ( $n=5$ /group) was excised, fixed in formalin, and embedded in paraffin for assessment of changes to the gastrointestinal tract suggestive of drug toxicity. Statistical significance was determined versus Control at day 16 post-dose using a one-sided twosample unequal variance t-test. 


\section{Effect of Dend-SN38 dose and schedule on anti-tumour efficacy}

To explore how the dose and schedule of the medium release Dend-SN38 conjugate influenced the therapeutic activity, an efficacy study was completed in mice bearing SW620 tumours. Animals were randomised for dosing when the average tumour volume reached $\sim 0.2 \mathrm{~cm}^{3}$. Mice were dosed $(\mathrm{n}=$ 9/group) once weekly for 4 cycles with saline (i.v.), irinotecan at $50 \mathrm{mg} / \mathrm{kg}$ (i.p.), or medium release Dend-SN38 at 2, 4, or $8 \mathrm{mg} / \mathrm{kg}$ (i.v.). At $24 \mathrm{~h}$ after the 4 th dose, 3 mice per group were euthanised to assess GI toxicity. The remaining mice were kept on study to evaluate tumour re-growth after the final dose. The effect of dose scheduling was also investigated by administering the medium release Dend-SN38 every 2 weeks for 2 cycles at 4 or $8 \mathrm{mg} / \mathrm{kg}$ (i.v.). Statistical significance was determined versus Control at day 23 post-dose using a one-sided two-sample unequal variance t-test.

\section{Tumour pharmacodynamic effect of irinotecan and Dend-SN38}

An acute dosing study was completed in SW620 tumour-bearing mice to compare the time course of tumour DNA damage. To ensure sufficient tumour material was available for analysis, animals were randomised for dosing when the average tumour volume reached $\sim 0.5 \mathrm{~cm}^{3}$. Mice ( $n=3-4 /$ group) were treated with a single dose of irinotecan at $50 \mathrm{mg} / \mathrm{kg}$ (i.p.) or medium release Dend-SN38 at 4 $\mathrm{mg} / \mathrm{kg}$ (i.v.). At $24 \mathrm{~h}, 72 \mathrm{~h}$, or $120 \mathrm{~h}$ post-dose, mice were euthanised and the tumour was excised and fixed in formalin and embedded in paraffin.

\section{Assessment of gastrointestinal toxicity}

To compare the severity of gastrointestinal toxicity caused by treatment with irinotecan and the Dend-SN38 conjugates, haematoxylin and eosin (H\&E)-stained sections (4-6 $\mu \mathrm{m})$ of formalin-fixed paraffin-embedded (FFPE) duodenum, jejunum, ileum, and colon were examined by a trained pathologist. Each segment was assessed and the severity of histopathological changes (crypt degeneration and atrophy) was graded using a semi-quantitative (0-5) scoring system (0, none; 1 , minimal; 2 , mild; 3 , moderate; 4 , marked; 5 , severe).

\section{Assessment of DNA damage in tumours}

Immunohistochemical staining for $\mathrm{\gamma H} 2 \mathrm{~A} . \mathrm{X}$ was completed to assess DNA damage in tumours. FFPE tumour sections $(4 \mu \mathrm{m})$ were dewaxed with xylene and rehydrated through graded ethanols to water. Antigen retrieval was performed in $\mathrm{pH} 9$ buffer at $110^{\circ} \mathrm{C}$ for $2 \mathrm{~min}$ in a RHS histoprocessor microwave. Endogenous enzyme activity was blocked with $3 \%$ hydrogen peroxide. Slides were incubated with serum free protein block (Dako) for 20 min before the primary antibody (antiphospho-histone H2A.X (Ser139); 1:300; Cell Signalling Technology) was added for $1 \mathrm{~h}$ at room temperature. The Dako Envision+ (anti-rabbit) peroxidase-labelled polymer system was applied for $30 \mathrm{~min}$, and slides were then incubated with 3,3'-diaminobenzidine (DAB; Dako) for $10 \mathrm{~min}$. Slides were counterstained with Carazzi's haematoxylin, dehydrated through graded ethanols to xylene, and coverslipped. Positive staining was measured using an in-house analysis developed using ImageScope (v11.2.0.780; Aperio). Statistical significance between treatments was determined using one-way ANOVA with Sidak's multiple comparisons post-test.

\section{Detection/localisation of SN-38 in tumour using Desorption Electrospray lonization - Mass Spectrometry Imaging (DESI-MSI)}

Snap-frozen tumour tissues were cryo-sectioned using a Leica CM3050 S (Leica Microsystems) cryostat to a thickness of $14 \mu \mathrm{m}$, thaw mounted onto Superfrost microscope slides and stored at $80^{\circ} \mathrm{C}$ until analysis. DESI imaging experiments were performed on a Thermo Scientific Q-Exactive instrument (Bremen, Germany) equipped with a 2D automated DESI source from Prosolia Inc. (Indianapolis, IN, USA) using a home-built sprayer assembly as described previously [42]. Detection of SN-38 was performed in negative ion mode as $[\mathrm{M}-\mathrm{H}]-$, while Irinotecan was detected in positive ion mode as $[\mathrm{M}+\mathrm{H}]+$. To allow detection of both compounds in a single imaging experiment, negative and positive ion mode were alternated during analysis. Analysis was performed at $R=$ 
70,000 mass resolving power and $50 \mathrm{~V}$ S-Lens Voltage. Methanol/water (95: $5 \mathrm{v} / \mathrm{v}$ ) was used as electrospray solvent at $4.5 \mathrm{kV}$ spray voltage and a flow rate of $1.5 \mu \mathrm{L} / \mathrm{min}$. Solvent was delivered using a Dionex Ultimate 3000 stand-alone nanoLC pump (Thermo Scientific). Nitrogen N4.8 was used as nebulising gas at a pressure of 7 bar. Distance between sprayer to sample surface was $1.5 \mathrm{~mm}$ while distance between sprayer and MS inlet was $7 \mathrm{~mm}$. The spray angle was set to $75^{\circ}$ while collection angle was set at $10^{\circ}$. The capillary temperature was set to $320^{\circ} \mathrm{C}$. Data was converted into centroid .imzML format using imzML converter version 1.1.4.5 [43] and visualised using MSiReader v0.05 [44]. All intensities shown are raw ion intensities. $1^{\text {st }}$ order linear interpolation was used for image generation. Samples were stained with H\&E post-DESI analysis and digitalised using a Leica Aperio AT2 slide scanner (Leica Microsystems).

\section{Measurements to determine the sensitivity of the DESI-MSI technique}

$\mathrm{SN}-38$ and irinotecan standard solutions dissolved in $50 \% \mathrm{MeOH}$ (diluted from a stock solution in DMSO) were spotted onto six adjacent tumour tissue sections. $1 \mu \mathrm{L}$ of standard solutions with concentrations ranging from $50 \mathrm{uM}$ to $0.1 \mathrm{uM}$ was spotted taking care to ensure that the standards were spotted onto comparable positions of the tissue sections. Tissue sections were subsequently analysed by DESI-MSI using the experimental parameters as described for the SN-38 localisation.

To calculate on-tissue concentrations, the assumption was made that standard solutions had distributed evenly throughout the tissue volume under the calibration spot. Tissue thickness was 10 $\mu \mathrm{m}$ for all sections and the area of the calibration spot was calculated using the number of pixels within a calibration spot with spatial resolution used in the experiment. Concentrations within the calibration spots ranged from $1146.8 \mu \mathrm{M}$ to $2.4 \mu \mathrm{M}$. Signal to noise $(\mathrm{S} / \mathrm{N})$ for the lowest concentration spot was determined to be on average 7.2 and 6.7 for $\mathrm{SN}-38$ and Irinotecan respectively, thus lying below the limit of quantification at $S / N=10$. For several pixels of the lowest concentration spot $\mathrm{S} / \mathrm{N}$ fell below 3 , indicating the signal was below the limit of detection.

\section{Results \& Discussion}

\section{Design and synthesis of SN-38 linkers and dendrimer conjugation}

After synthesising a dendrimer platform with the desired size, surface-modification, and biocompatibility [34], we then developed $\mathrm{SN}-38$ linkers with a range of release rates to explore differential SN-38 profiles over time. Three linker chemistries were utilised to tune the release rate: a primary amine carbamate, an ester, and a secondary amine carbamate, respectively (Scheme 1). To generate fast and medium release linkers, the primary amine carbamate and ester linkers were synthesised to have sufficient distance from the amide of the linker itself (carbamate) or from the amide of the dendrimer coupling (carbamate and ester) to avoid anchimeric assistance to hydrolytic breakdown. This effect has been shown to have a significant impact on release rates [45], and was exploited to increase release rate. Inclusion of a triazole in the linker design as demonstrated here would be expected to reduce this effect by extending and rigidifying the linker such that any transition state involving anchimeric assistance would be highly strained and energetically disfavoured. To generate a fast release linker, the $1^{\circ}$ amine carbamate was used for its increased susceptibility to chemical hydrolysis, which we hypothesise is due to a mechanism involving the formation of an intermediate isocyanate. This isocyanate decomposes rapidly in the presence of water to give a primary amine and carbon dioxide by-product. Hence, to produce a slow release linker, we investigated the $\mathrm{N}$-methylated $2^{\circ}$ amine carbamate, which cannot undergo this type of release mechanism. Consistent with our hypothesis, this linker exhibited a slower release rate. This exemplifies how the dendrimer platform can be coupled with unique linker chemistries to achieve different release rates to provide desired drug profiles. 

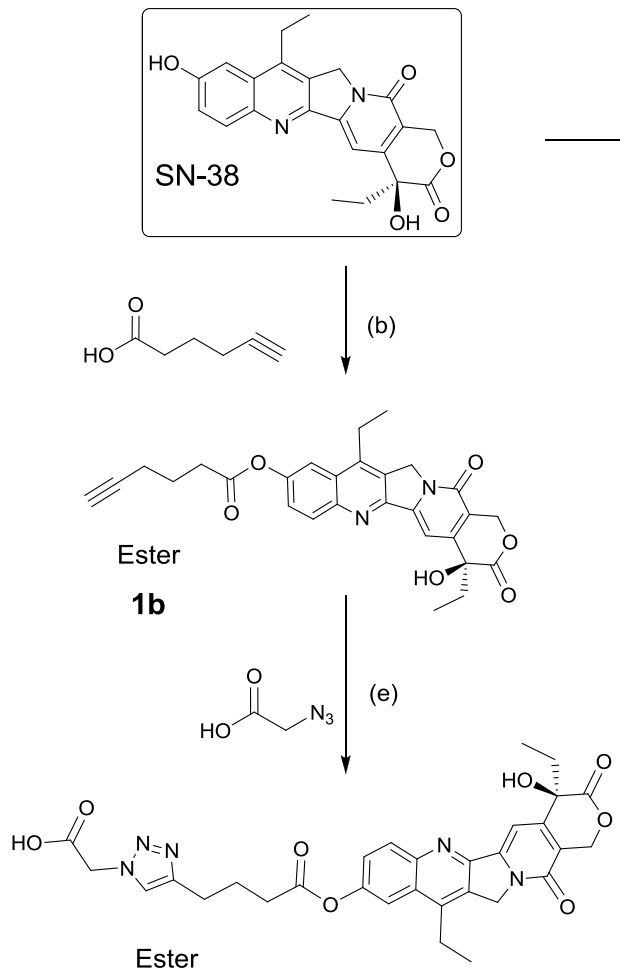

1b'

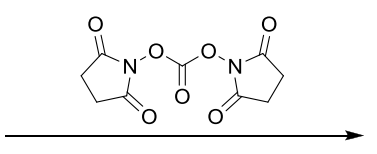

(a)<smiles>C#CCNC(=O)CCCCCN</smiles>

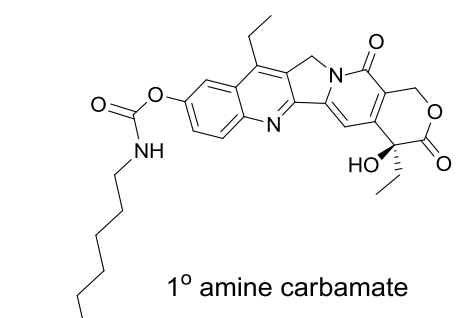

1a

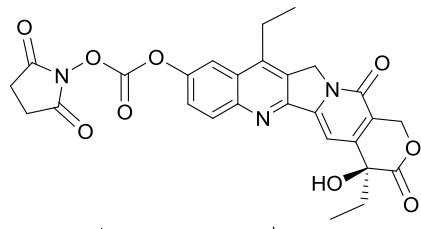

(d)<smiles>C#CCNC(=O)CNC</smiles>

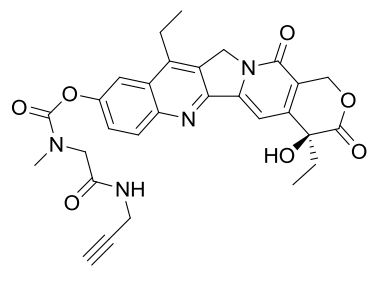

$1 \mathrm{c}$

Scheme 1. Synthesis routes for linker-SN38 compounds 1a-c. (a) ACN/THF, DMAP, RT. (b) DMF, EDC/DMAP RT, (c + d) DCM, DIPEA, DMAP (e) DMF, sodium ascorbate, copper Il sulphate, RT.

Initially, linkers 1a-c were designed with alkyne groups to conjugate to an azide-modified dendrimer through click chemistry. The methodology for the dendrimer synthesis and linker-SN38 conjugation is outlined in Scheme 2. At a later stage, an alternative route of synthesis was made for linker $1 \mathrm{~b}$ (linker $1 b^{\prime}$ ) to avoid the use of copper click chemistry in the presence of the polyoxazoline-modified dendrimer. Polyoxazoline has been reported to have an affinity for copper in click reactions [46] which, although not observed here, was still avoidable by carrying out the purification on the linker before conjugating to the dendrimer.
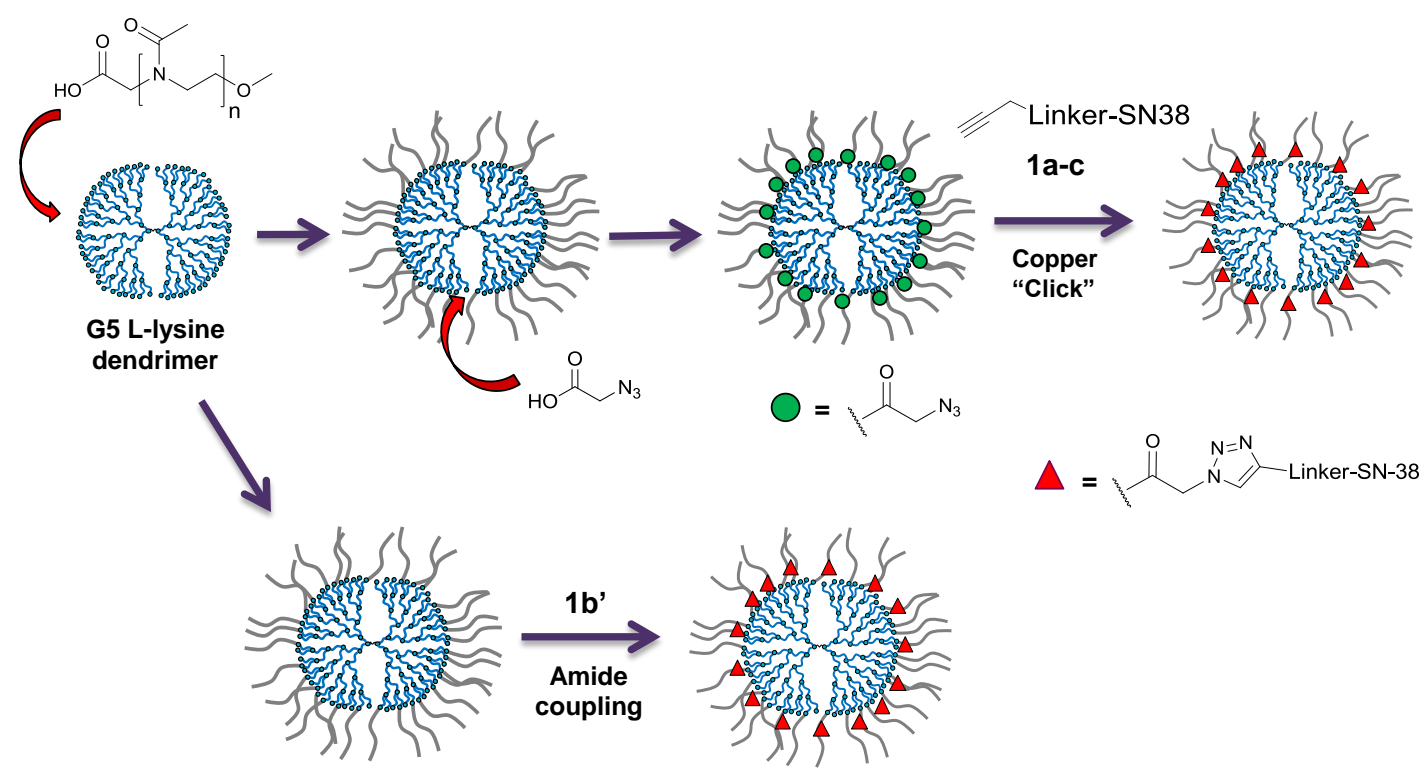


\section{Scheme 2. Synthetic route to polyoxazoline-modified dendrimers with linker-SN38 conjugation.}

The drug loading was consistent by employing click chemistry to conjugate SN-38 linkers 1a-c to the dendrimer (Table 1). Unreacted SN-38 linker was efficiently removed from the conjugate using a LH20 sephadex size exclusion column with methanol eluent; unreacted linker was not detectable by HPLC-UV (LoD $~ 0.1 \mu \mathrm{g} / \mathrm{mL}$ ). Presumably, the unbound SN-38 detected in sample 2 a arose from the release of some of the drug during the evaporation and solvent changeover process, since this conjugate had the fastest release rate. The unbound $\mathrm{SN}-38$ in $2 b^{\prime}$ was a small amount of residual drug leftover from the purification process.

Conjugate $2 b^{\prime}$ was synthesised differently: the linker was conjugated to the dendrimer through an amide coupling step and was purified by ultrafiltration afterwards. This was the most efficient method for the preparation of the conjugate since it removed an ultrafiltration purification step from the dendrimer after the azide modification and was found to be a better method for larger quantities of material. All of the dendrimer conjugates had ca. $8 \mathrm{wt} . \%$ of SN-38, which equates to 25 drug molecules per dendrimer on average. Residual functional groups were not quantified but are expected to be minimal given the excess of drug-linker used and the consistencies in the loadings. The solubility of the conjugates remained very good but reduced in comparison to the native dendrimer. The structural representation of each dendrimer-SN38 conjugate (Dend-SN38) can be found in Supporting Information Scheme S1. A representative GPC chromatogram and DLS spectra have also been included for conjugate $2 b^{\prime}$ in the Supporting Information Fig. S1.

Table 1. SN-38 loading and non-conjugated (free) SN-38 for the different dendrimer conjugates.

\begin{tabular}{lccc}
\hline Dendrimer description & $\begin{array}{c}\text { Release } \\
\text { description }\end{array}$ & $\begin{array}{c}\text { Conjugated SN-38 } \\
\text { wt.\% }\end{array}$ & $\begin{array}{c}\text { Free SN-38 in } \\
\text { sample wt.\% }\end{array}$ \\
\hline $\mathbf{2 a}\left(1^{\circ}\right.$ amine carbamate) & Fast & 8.1 & 0.2 \\
$\mathbf{2 b}(\text { Ester })^{¥}$ & Medium & 8.3 & $\mathrm{ND}$ \\
$\mathbf{2 b}^{\prime}(\text { Ester })^{\dagger}$ & Medium & 7.7 & 0.17 \\
$\mathbf{2 c}\left(2^{\circ}\right.$ amine carbamate) & Slow & 8.5 & ND \\
\hline$=$ Not detected (by HPLC-UV). ${ }^{*}$ Conjugated by click chemistry. ${ }^{\dagger}$ Conjugated through amide coupling.
\end{tabular}

\section{Dend-SN38 release rates}

The release rates for SN-38 from the Dend-SN38 conjugates were measured in PBS, and subsequently in plasma to mimic the in vivo situation more closely. The release rates measured for the Dend-SN38 conjugates 2a-c in plasma (Fig. 1B) in vitro were found to differ from those measured in PBS (Fig. 1A), presumably due to enzymatically mediated processes, despite the presence of the polyoxazoline on the surface of the dendrimer. The range of in vitro plasma release half-lives for the three Dend-SN38 conjugates was determined to be $2.5 \mathrm{~h}$ ("fast release"), $21 \mathrm{~h}$ ("medium release"), and $72 \mathrm{~h}$ ("slow release") (Fig. 1B). Based on the drug loading and a $21 \mathrm{~h}$ release rate, it was predicted that the medium release Dend-SN38 would achieve the desired sustained exposure to therapeutic concentrations of SN-38. The fast and slow release linkers were designed to give greater insight into the relationship between efficacy and toxicity by providing exposure profiles outside of the target plasma level.

Plasma SN-38 pharmacokinetics studies were performed in mice to confirm whether there would be a prolonged, therapeutic level of SN-38 in the circulation in vivo (Fig. 1C). The plasma half-life of SN38 (carboxylate form) itself in vivo is less than $0.5 \mathrm{~h}$ (Supporting Information Fig. S2) and previous 
reports have shown that the $\mathrm{SN}-38$ generated after administration of irinotecan is rapidly cleared $[47,48]$. Of the three Dend-SN38 conjugates we designed, only the medium release conjugate achieved the desired sustained exposure of SN-38 in vivo. Therapeutic concentrations of SN-38 were measured up to $96 \mathrm{~h}$ after the administration of this conjugate. As expected for the fast release conjugate, the plasma levels of SN-38 quickly diminished within $10-20 \mathrm{~h}$ after administration. This is consistent with the rapid release of SN-38 from the conjugate $\left(t_{1 / 2}=2.5 \mathrm{~h}\right)$ and subsequent rapid clearance of liberated SN-38. The slow release conjugate was designed to provide a low but consistent exposure to $\mathrm{SN}-38$. However, a short burst release was observed, followed by an equilibrated concentration of SN-38, which was below the limit of detection of the instrument (UPLC-MS/MS LoD = $5 \mathrm{nM}$ ). Given that there was no free drug detected in the sample by HPLC-UV, the rationale for the early burst may have originated from some enzymatic action on the more easily accessible linkers, since enzymatic cleavage of secondary amine carbamates is known [49]. It is also possible that demethylation of enzyme-accessible carbamate groups could have occurred and would also have led to faster release of $\mathrm{SN}-38$. Some ex vivo release during sample storage and preparation may have been a minor contributing factor. Interestingly, the total SN-38 plasma profile (i.e. conjugated plus free $\mathrm{SN}-38$ ) showed that the slow release conjugate was being cleared faster than the medium release conjugate, despite the slower release rate. This is thought to be driven by the residual functional groups exposed by the linkers after drug release, i.e. a carboxyl group for the ester (medium release) versus a $2^{\circ}$ amine for the carbamate (slow release), which could be recognised by the mononuclear phagocyte system and cleared from circulation at different rates.[50]

A.

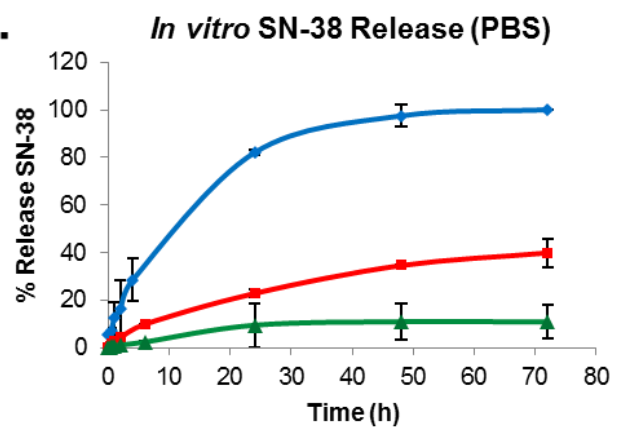

C.

Plasma Free SN-38 Concentration (In vivo)

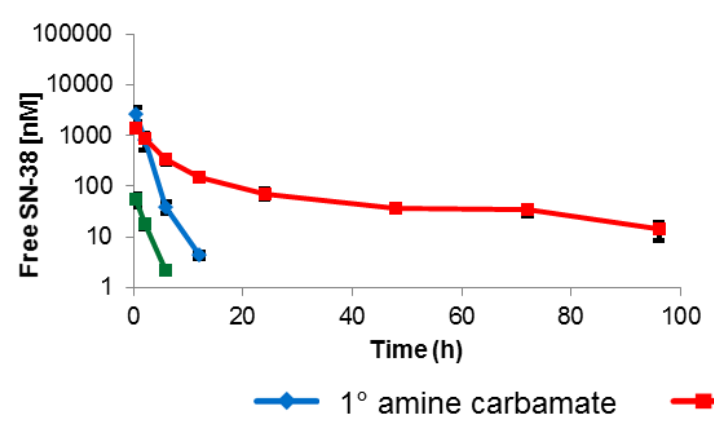

(Fast)
B.

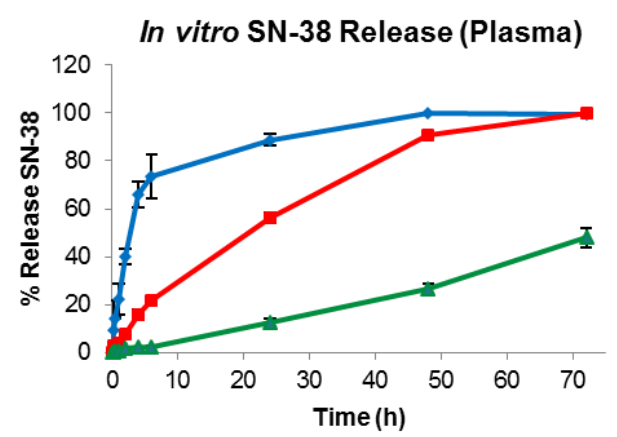

D.

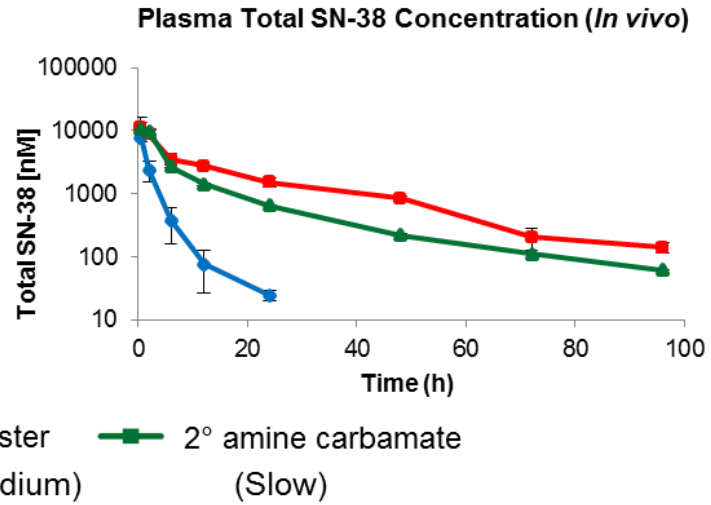

Figure 1. (A) In vitro release of SN-38 in PBS. (B) In vitro plasma release (Wistar rat). (C) In vivo pharmacokinetics of SN-38 liberated from the Dend-SN38 conjugates (2a-c). (D) In vivo pharmacokinetics for total SN-38 (liberated + conjugated).

In vivo efficacy and safety 
The relative anti-tumour efficacy of the Dend-SN38 conjugates at $4 \mathrm{mg} / \mathrm{kg}$ versus irinotecan was determined using mice bearing subcutaneous SW620 colorectal xenografted tumours. This model was selected for its well-characterised response to irinotecan. Dend-SN38 conjugates were administered weekly intravenously, at doses expected to achieve therapeutic concentrations of SN38 for different periods of time, based on in vitro and in vivo release and pharmacokinetic studies. By mass, irinotecan is $\sim 67 \% \mathrm{SN}-38$. Irinotecan was dosed at the maximum tolerated i.v. and i.p. doses to test two different profiles of plasma exposure and local drug concentration, with the SN-38 concentrations related proportionally. Intravenous administration achieves a high initial concentration, followed by rapid clearance; intraperitoneally dosed irinotecan reaches the plasma more slowly and achieves more prolonged drug exposure with a lower $\mathrm{C}_{\max }$. This more closely mimics the clinical standard-of-care of irinotecan infusion.

The SW620 xenograft model has a well characterised, but modest, response to irinotecan. Both i.p. and i.v. irinotecan treatment caused a slight reduction in tumour growth ( $50 \%$ inhibition, $\mathrm{P}<0.01$ and $19 \%$ inhibition, $\mathrm{P}>0.05$, respectively), but the tumours continued to progress (Fig. $2 \mathrm{~A}$ ). Changes in the growth rate of i.p. irinotecan-treated tumours were observed by day 3 post-dose, whilst little response was observed for the i.v. treatment. This supports the value of more prolonged input of drug into plasma following i.p. dosing. In contrast to the modest anti-tumour effect of irinotecan, treatment with the medium release Dend-SN38 led to significant tumour regression $(P<0.001$; Fig. 2A). The deviation from saline controls occurred on day 5 post-dose (versus day 3 post-dose for irinotecan) and tumour regression was evident by the third cycle of dosing. At the end of study, medium Dend-SN38 treatment had caused 69\% tumour regression, while regression was not observed with irinotecan treatment. Highlighting the relationship between drug exposure profile and anti-tumour efficacy, the fast and slow release conjugates gave no anti-tumour effect (Fig. 2A). This is consistent with the low plasma concentrations of released $\mathrm{SN}-38$ seen in the in vivo pharmacokinetic evaluation (Fig. 1C). The sustained therapeutic concentration of SN-38 delivered by the medium release conjugate resulted in more than a 3 -fold reduction in average tumour volume at the end of the study. It will be important to test the robustness of the Dend-SN38 conjugate across a panel of pre-clinical models to develop greater insight into its clinical potential.

A.

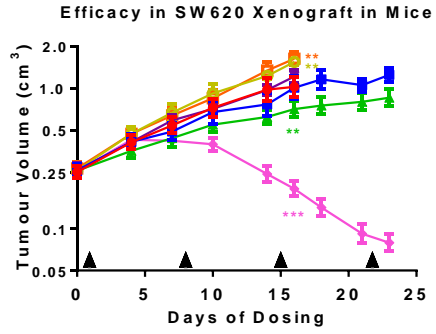

C.

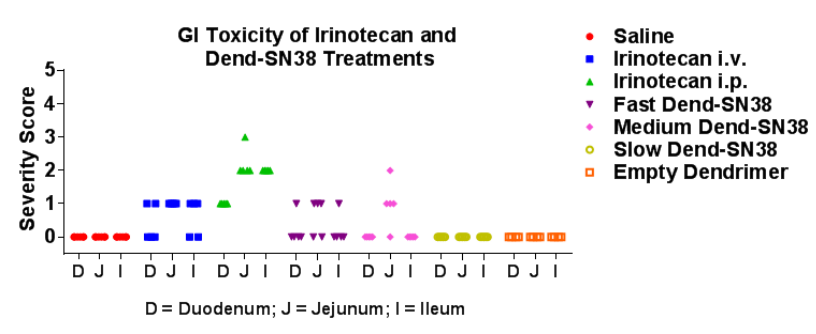

B.
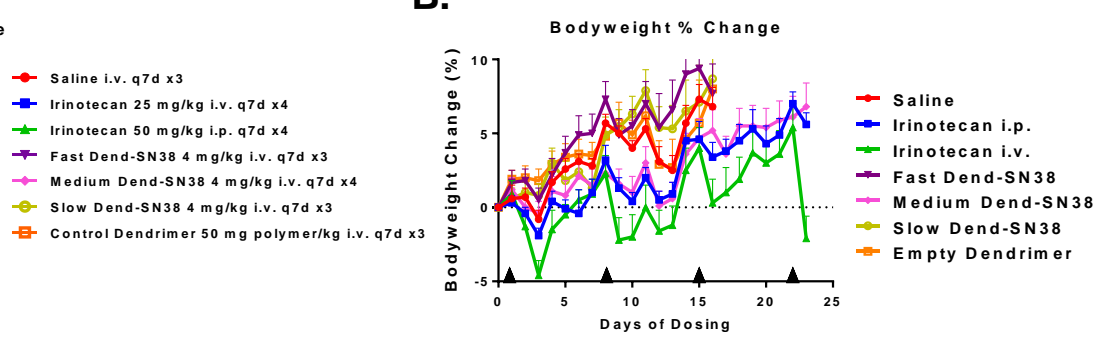

D.

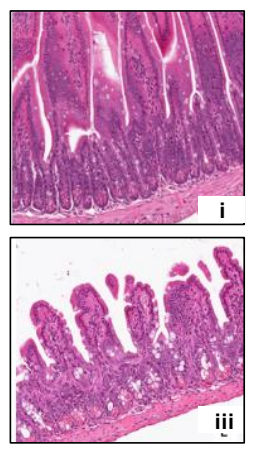

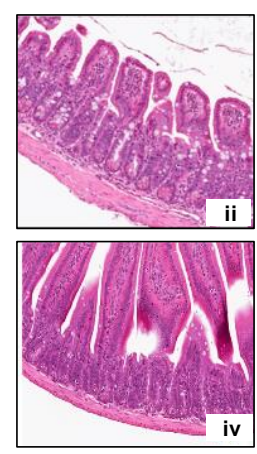

Figure 2. Efficacy and gastrointestinal toxicity of Dend-SN38 conjugates (2a-c) versus irinotecan both i.p. and i.v. at the maximum tolerated dose. (A) Mouse SW620 anti-tumour efficacy plot dosing q7d. (B) Mean group bodyweight change during efficacy study. (C) Gastrointestinal toxicity 


\section{score for crypt atrophy; 0 = no change, 5 = severe changes. (D) Representative gastrointestinal tract cross sections of crypt epithelium at $24 \mathrm{~h}$ post-last dose; (i) Control, (ii) Irinotecan i.v., (iii) Irinotecan i.p., (iv) Medium release Dend-SN38. ${ }^{* *}$ and ${ }^{* * *}=\mathrm{P}<0.01$ and $\mathrm{P}<0.001$ versus Saline at Day 16, respectively.}

Pre-clinically and clinically, treatment with irinotecan can be limited by certain toxicities, including gastrointestinal toxicity [51]. Gastrointestinal toxicity resulting from irinotecan treatment is thought to be driven by a number of mechanisms, including direct conversion of irinotecan into $\mathrm{SN}-38$ in the intestines, and enzymatic cleavage of the metabolite SN-38G (SN-38 glucuronide) back into SN-38 during enterohepatic circulation and reabsorption of the drug [52]. These toxicities can be observed pathologically in mice. To investigate the effect of repeated doses of the different treatments on the gastrointestinal tract, the toxicity was assessed at the end of the study. A pathologist-based assessment of H\&E-stained samples of the gastrointestinal tract was performed (see Fig. 2D for representative images). Baseline toxicity profiles were established using i.v. and i.p. irinotecan treatments as positive controls. Irinotecan treatment resulted in minimal to mild degenerative effects within the small intestinal crypt epithelium, with generally more severe concomitant atrophic changes with i.p. irinotecan treatment (Fig. 2C). This most likely reflects the greater local gastrointestinal exposure [53] and extended plasma exposure [54] to irinotecan/SN-38 with the i.p. dosing. The pathological analysis of crypt degeneration correlates with mean mouse bodyweight loss for the different treatment groups: irinotecan i.p. caused the greatest bodyweight loss, with smaller weight fluctuations observed for irinotecan i.v. and medium release dendrimer conjugate, and good tolerability for other treatments (Fig. 2B).

The toxicity of the dendrimer conjugates was compared directly to the baseline irinotecan toxicity profiles. Each conjugate presented a unique profile of toxicity. While the slow release dendrimer conjugate had no impact on the gastrointestinal tract, it also did not exert any therapeutic effect. The findings suggest that the concentration of SN-38 in the tumour was too low to provide efficacy. Similarly, the fast release dendrimer conjugate showed no anti-tumour activity. However, this is thought to be due to the rapid release of the drug and subsequent rapid clearance of the free drug, therefore, not providing a prolonged exposure of the drug required in the tumour for efficacy. Moreover, this conjugate caused minimal to mild toxicity throughout the small intestine (similar to i.v. irinotecan treatment), which is thought to be due to higher initial plasma concentrations resulting from more rapid drug release. This suggests that the plasma drug exposure is critical to managing the toxicity of irinotecan/SN-38. In contrast, the significantly improved efficacy of the medium release Dend-SN38 conjugate was accompanied by reduced gastrointestinal effects relative to both irinotecan groups and the fast release Dend-SN38. No atrophic effects were observed in the ileum or duodenum, though a small number of animals showed minimal to mild crypt atrophy in the jejunum after treatment with the medium release dendrimer conjugate. These observations are consistent with a reduction in the plasma $\mathrm{C}_{\max }$ of $\mathrm{SN}-38$ when administered as a polymer therapeutic with a prolonged release rate, thus a reduced distribution to the liver and intestines leading to lower toxicity.

The combination of potent tumour regression and good gastrointestinal tolerability with the medium release dendrimer conjugate is a significant improvement in the therapeutic index of SN-38. The superiority of the efficacy of the medium release Dend-SN38 over the slow and fast release conjugates made it the logical formulation to investigate further. Additional studies were completed to explore the efficacy and pharmacodynamic effects of the medium release conjugate. Henceforth the medium release Dend-SN38 conjugate will be referred to as DEND-38. 
A.

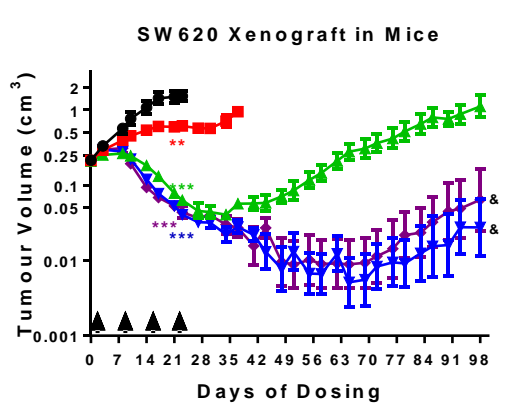

C.

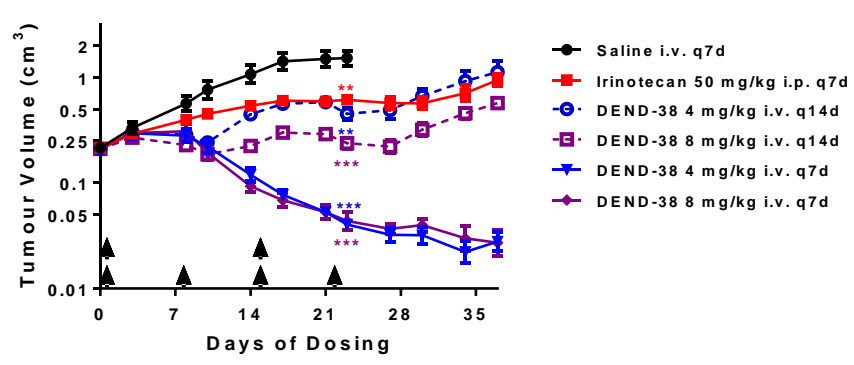

B.

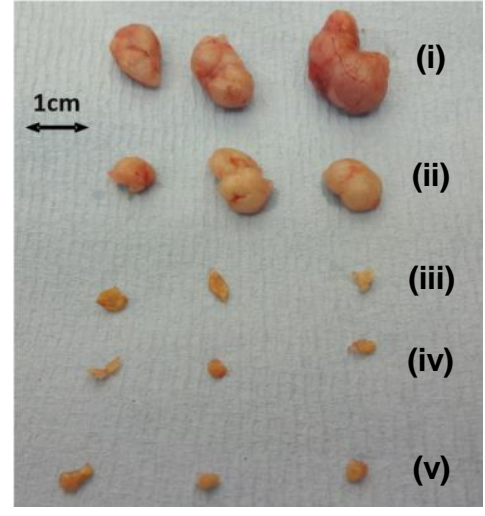

D. (i)
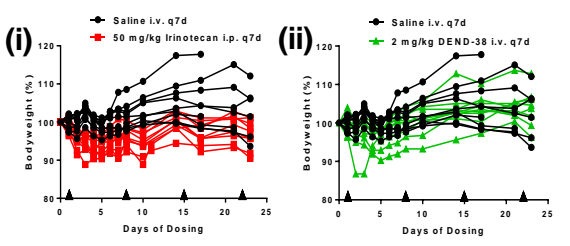

(iii)

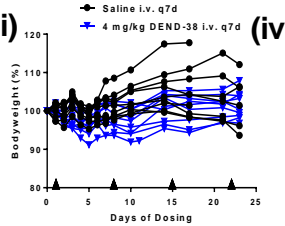

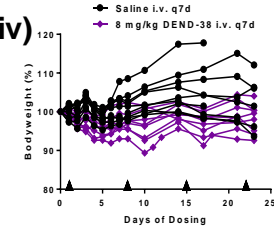

Figure 3. (A) Dose-dependent efficacy for DEND-38 and 72 day re-growth period following final dose. (B) Picture of tumours excised at $24 \mathrm{~h}$ post-last dose (day 23) representing treatment with (i) saline, (ii) irinotecan i.p., (iii) DEND-38 2 mg/kg, (iv) DEND-38 $4 \mathrm{mg} / \mathrm{kg}$, and (v) DEND-38 $8 \mathrm{mg} / \mathrm{kg}$. (C) Schedule-dependent efficacy for weekly versus fortnightly administration of DEND-38 at 4 and $8 \mathrm{mg} / \mathrm{kg}$. (D) Individual mouse bodyweights during study dosing period. ${ }^{* *}$ and $* * *=P<0.01$ and $P<0.001$ versus Saline at Day 23, respectively; $\&=1$ mouse without visible tumour at end of study.

The dose-response of DEND-38 was explored in SW620 tumour-bearing mice. As observed above, treatment with the standard-of-care irinotecan slowed tumour growth $(\mathrm{P}<0.01$; Fig. $3 \mathrm{~A}-\mathrm{C})$. In contrast, 2, 4 and $8 \mathrm{mg} / \mathrm{kg}$ DEND-38 produced tumour regression after two treatments (Fig. 3A-C). After four treatments of DEND-38, the majority of tumours at each dose had regressed to less than $0.05 \mathrm{~cm}^{3}(\mathrm{P}<0.001)$. Both the 4 and $8 \mathrm{mg} / \mathrm{kg}$ DEND-38 dose levels produced the same rate of tumour regression in this model. The significant tumour regression observed at these doses did not necessitate further dose escalation in this model, thus, the maximum tolerated dose was not established. All three dose levels of DEND-38 treatment were well tolerated (Fig. 3D). Individual animal bodyweights are presented in Supporting Information Fig. S3. The broad therapeutic index of DEND-38 provides the opportunity to utilise doses above $8 \mathrm{mg} / \mathrm{kg}$ in other less sensitive models to achieve efficacy.

The tumour regression achieved in both the 4 and $8 \mathrm{mg} / \mathrm{kg}$ treatment groups (peaking at $98 \%$ at day 55 and $96 \%$ at day 48 , respectively) was maintained for $\sim 7-8$ weeks after dosing cessation. After this point, slow re-growth was observed. The anti-tumour response and re-growth for all individual animals is presented in Supporting Information Fig. S4. At 10 weeks after the final dose, 1/6 mice from both groups still showed no evidence of visible tumour. Treatment with $2 \mathrm{mg} / \mathrm{kg}$ DEND-38 produced a delayed initial tumour regression relative to the 4 and $8 \mathrm{mg} / \mathrm{kg}$ doses. Moreover, tumour re-growth was significantly more rapid at the lowest dose level (peaking at $82 \%$ at day 34 ), showing a dose-response effect. While $2 \mathrm{mg} / \mathrm{kg}$ DEND-38 represents a low effective dose, future studies will investigate tumour control at lower doses. 
The effect of weekly (every 7 days) and fortnightly (every 14 days) dosing schedules was compared to explore the importance of increased AUC versus duration of exposure in driving anti-tumour efficacy. Substantially poorer activity was observed with the fortnightly schedule of DEND-38 at both 4 and $8 \mathrm{mg} / \mathrm{kg}$ (Fig. 3C). Over 14 days, two doses of $4 \mathrm{mg} / \mathrm{kg}$ achieved tumour regression, while a single dose of $8 \mathrm{mg} / \mathrm{kg}$ achieved tumour control until day 8-10, and tumour growth resumed by day 14 post-dose. These data suggest that weekly administrations are required and sufficient to maintain therapeutic SN-38 concentrations in tumour. Fortnightly administration demonstrated dosedependent anti-tumour efficacy, with $8 \mathrm{mg} / \mathrm{kg}$ treatment being superior to $4 \mathrm{mg} / \mathrm{kg} \quad(P<0.001 \mathrm{vs}$. $\mathrm{P}<0.01$, respectively; Fig. $3 \mathrm{C}$ ). This is supported by data showing that plasma $\mathrm{SN}-38$ concentrations increased with dose (Fig. 3D). A re-challenge of the tumours at day 15 caused a moderate reduction in tumour size (Fig. 3C).

The data show that drug release rate influences both efficacy and toxicity. The flexibility in the design of the linker provides the opportunity to further optimise the release rate and dosing schedule to maximise the therapeutic window. Future pre-clinical work in different tumour types and in combination with other agents will seek to understand the drivers of activity, response to rechallenge, and therapeutic potential with other therapies. Patient tumours typically present with a more complex tumour microenvironment than do standard pre-clinical xenograft models. As with all novel nanomedicine technologies optimised pre-clinically, it will be important to determine whether the efficacy observed in the SW620 model translates to other more patient-relevant models and across different genetic backgrounds [18].

A.

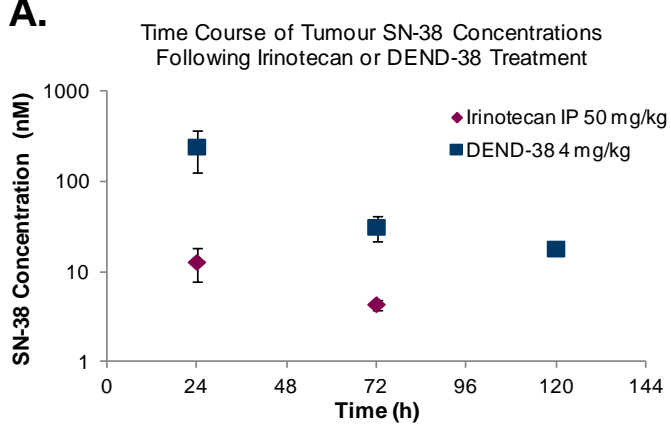

C.

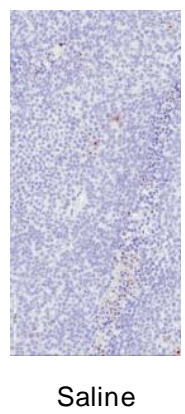

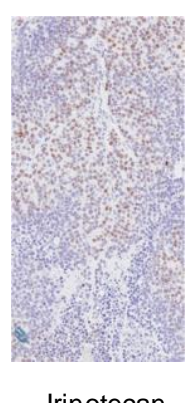

Irinotecan

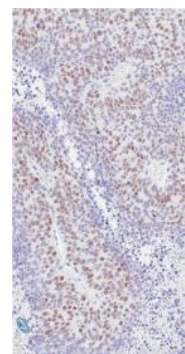

DEND-38
B.

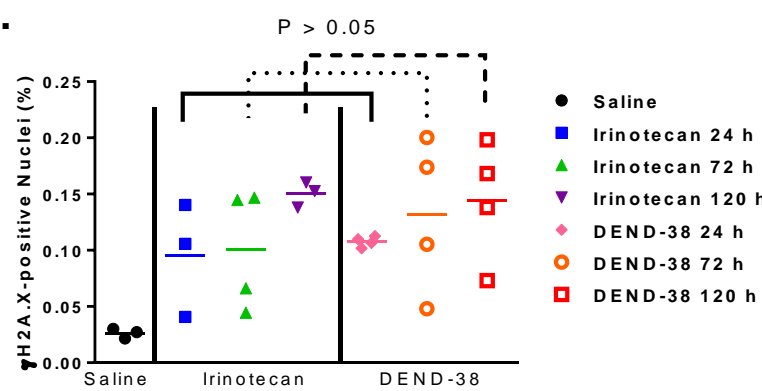

D.

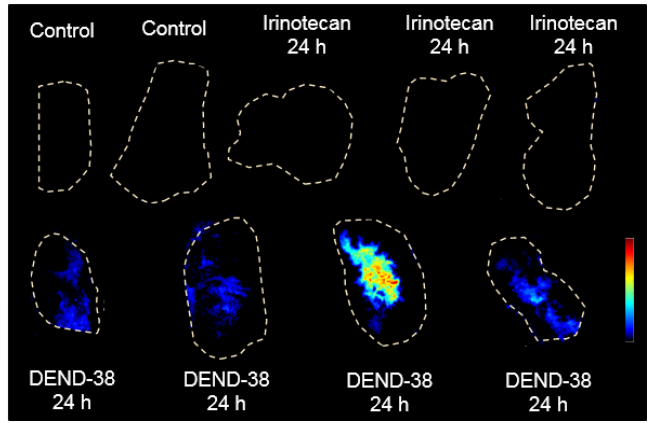

Figure 4. Tumour pharmacokinetics and pharmacodynamic effects of irinotecan and DEND-38 treatment. (A) SN-38 concentration in tumours at 24,72 , and $120 \mathrm{~h}$ post-dose. (B) DNA damage staining for $\mathrm{YH} 2 \mathrm{~A}$.X-positive nuclei in tumours at 24,72 , and $120 \mathrm{~h}$ post-dose of irinotecan or DEND-38. $P>0.05$ between treatments at each time point. (C) Representative images of $\gamma \mathrm{H} 2 \mathrm{~A} . \mathrm{X}$ staining in tumours at $24 \mathrm{~h}$ post-dose. (D) DESI-MS detection of SN-38 in tumour sections at $24 \mathrm{~h}$ post-dose of irinotecan i.p. at $50 \mathrm{mg} / \mathrm{kg}$ or DEND-38 i.v. at $4 \mathrm{mg} / \mathrm{kg}$. H\&E-stained tumour sections shown in Supporting Information Fig. S5. 
To investigate the time course of drug accumulation and DNA damage following exposure to irinotecan/SN-38, tumour pharmacokinetics and pharmacodynamic effect were analysed up to 5 days post-dose. Tumours were harvested and divided in half for IHC analysis of DNA damage or MS imaging of drug distribution and subsequent SN-38 quantification. Quantification of SN-38 in tumour homogenates revealed that treatment with DEND-38 achieved $\sim 10$-fold greater accumulation of SN38 in tumours than did treatment with irinotecan (Fig. 4A). This was observed at all three time points tested. DEND-38 treatment maintains sustained levels of SN-38 in tumours for at least $120 \mathrm{~h}$ postdose. In contrast, in the irinotecan-treated group, SN-38 concentrations dropped below the target concentration by $72 \mathrm{~h}$ post-dose, and were no longer detectable at $120 \mathrm{~h}$ (Fig. 4A).

Treatment with a single dose of either DEND-38 or the clinical standard-of-care irinotecan causes sustained DNA damage in tumours (Fig. 4B,C), but does not affect cell proliferation in tumours (as determined by Ki67 staining; data not shown). After a single dose, DNA damage can be observed at $24 \mathrm{~h}$ and persists for at least 5 days. This implies that the DNA damage triggered by irinotecan persists for several days after the drug is cleared from the tumour. This study demonstrates proof of mechanism of action of the anti-tumour effect of DEND-38, attributed to the accumulation of drug in the tumour (see below). While there is not a significant difference in the level of DNA damage after the initial dose of irinotecan or DEND-38 ( $P>0.05)$, there is also little differentiation in the tumour growth curves for the irinotecan and DEND-38 treatment groups after a single dose. Future studies will be required to investigate DNA damage after repeated cycles of dosing and will strive to elucidate the biological effects beyond DNA damage that underpin the differential efficacy achieved by DEND-38 and irinotecan treatment.

To build on tumour pharmacokinetic analyses and provide insight into the cellular level distribution of drug throughout the tumour, mass spectrometry imaging was employed to characterise the distribution of SN-38 and irinotecan in tumour slices at $24 \mathrm{~h}$ post-dose. In the DEND-38-treated tumours, SN-38 was detectable in all four tumours analysed (Fig. 4D). Drug was localised peripherally and in focalised regions in the core of the tumours. In the SW620 model, the core is often a region of lower cellularity, necrosis, or increased fluid, which may allow for enhanced distribution and could serve as a drug depot. SN-38 was not detectable at $72 \mathrm{~h}$ or $120 \mathrm{~h}$ after the DEND-38 dose (Fig. 4D), as it had fallen below the limit of detection (approximately $200 \mathrm{nM}$; see Supporting Information Fig. S6). This is in agreement with concentration data derived using LC-MS showing SN-38 concentrations to be below $100 \mathrm{~nm}$ at $72 \mathrm{~h}$ and $120 \mathrm{~h}$. In irinotecan-treated tumours, both free SN-38 and irinotecan were below the limit of detection in all three tumours tested at $24 \mathrm{~h}$ (Fig. 4D). These data present the drug distribution in a single, central tumour slice. Although not the focus of this article, it will be important to build more detailed insight into the distribution of the drug using a series of tumour slices and a panel of tumour models.

\section{Conclusions}

We have shown proof-of-principle that a novel dendrimer technology with SN-38, the active metabolite from irinotecan, conjugated through a linker can be used in the treatment of SW620 human colon cancer xenografts. Tuning the release rate of $\mathrm{SN}-38$ from the dendrimer conjugates made it possible to explore a range of drug exposure profiles. While the present study focused on generating conjugates with three distinct drug release profiles in mouse plasma, for evaluation of the panel in pre-clinical mouse studies, future work will be required to fine-tune the system to achieve appropriate release rates in various species, including humans, to translate this system to the clinic. The medium release dendrimer-SN38 conjugate with a half life of $21 \mathrm{~h}$ achieved sustained therapeutic concentrations of SN-38 in plasma and tumour compared with irinotecan. We evaluated the dose-response for two different schedules to investigate the impact of dose and regimen on the 
efficacy of the medium release dendrimer conjugate. We found that a dose of $4 \mathrm{mg} / \mathrm{kg}$ together with a weekly dosing schedule gave substantial tumour response and led to survival of the treated mice 72 days following the final dose. The use of DESI-MS in addition to UPLC-MS and DNA damage staining elucidated that whilst irinotecan caused DNA damage to large numbers of the tumour cells, sustained exposure to $\mathrm{SN}-38$ over an extended period was required to attain the desired tumour regression. Finally, we have developed a nanomedicine system that can deliver a dramatically improved therapeutic index for SN-38, with both substantially increased efficacy and reduced toxicity versus the prodrug irinotecan.

\section{Acknowledgements}

We thank the AstraZeneca Innovative Medicines postdoctoral research scheme. We gratefully acknowledge Rajesh Odedra for valuable discussions. This research was funded by AstraZeneca.

\section{References}

[1] D. Cook, D. Brown, R. Alexander, R. March, P. Morgan, G. Satterthwaite, M.N. Pangalos, Lessons learned from the fate of AstraZeneca's drug pipeline: a five-dimensional framework, Nat Rev Drug Discov, 13 (2014) 419-431.

[2] Y. Pommier, Drugging topoisomerases: lessons and challenges, ACS chemical biology, 8 (2013) 8295.

[3] Y. Kawato, M. Aonuma, Y. Hirota, H. Kuga, K. Sato, Intracellular roles of SN-38, a metabolite of the camptothecin derivative CPT-11, in the antitumor effect of CPT-11, Cancer research, 51 (1991) 41874191.

[4] J. Shi, P.W. Kantoff, R. Wooster, O.C. Farokhzad, Cancer nanomedicine: progress, challenges and opportunities, Nat Rev Cancer, 17 (2017) 20-37.

[5] H. Maeda, Toward a full understanding of the EPR effect in primary and metastatic tumors as well as issues related to its heterogeneity, Advanced drug delivery reviews, 91 (2015) 3-6.

[6] S. Palakurthi, Challenges in SN38 drug delivery: current success and future directions, Expert opinion on drug delivery, 12 (2015) 1911-1921.

[7] X. Zhang, K. Tang, H. Wang, Y. Liu, B. Bao, Y. Fang, X. Zhang, W. Lu, Design, Synthesis, and Biological Evaluation of New Cathepsin B-Sensitive Camptothecin Nanoparticles Equipped with a Novel Multifuctional Linker, Bioconjugate chemistry, 27 (2016) 1267-1275.

[8] V. Bala, S. Rao, B.J. Boyd, C.A. Prestidge, Prodrug and nanomedicine approaches for the delivery of the camptothecin analogue SN38, Journal of controlled release : official journal of the Controlled Release Society, 172 (2013) 48-61.

[9] H. Zhang, J. Wang, W. Mao, J. Huang, X. Wu, Y. Shen, M. Sui, Novel SN38 conjugate-forming nanoparticles as anticancer prodrug: in vitro and in vivo studies, Journal of controlled release : official journal of the Controlled Release Society, 166 (2013) 147-158.

[10] N. Mosallaei, A. Mahmoudi, H. Ghandehari, V.K. Yellepeddi, M.R. Jaafari, B. Malaekeh-Nikouei, Solid lipid nanoparticles containing 7-ethyl-10-hydroxycamptothecin (SN38): Preparation, characterization, in vitro, and in vivo evaluations, European journal of pharmaceutics and biopharmaceutics : official journal of Arbeitsgemeinschaft fur Pharmazeutische Verfahrenstechnik e.V, 104 (2016) 42-50.

[11] Y. Yao, L. Yu, X. Su, Y. Wang, W. Li, Y. Wu, X. Cheng, H. Zhang, X. Wei, H. Chen, R. Zhang, L. Gou, $X$. Chen, Y. Xie, B. Zhang, Y. Zhang, J. Yang, Y. Wei, Synthesis, characterization and targeting chemotherapy for ovarian cancer of trastuzumab-SN-38 conjugates, Journal of controlled release : official journal of the Controlled Release Society, 220 (2015) 5-17. 
[12] L. Lu, Y. Zheng, S. Weng, W. Zhu, J. Chen, X. Zhang, R.J. Lee, B. Yu, H. Jia, L. Qin, Complete regression of xenograft tumors using biodegradable mPEG-PLA-SN38 block copolymer micelles, Colloids and Surfaces B: Biointerfaces, 142 (2016) 417-423.

[13] A. Awada, A.A. Garcia, S. Chan, G.H.M. Jerusalem, R.E. Coleman, M.T. Huizing, A. Mehdi, S.M. O'Reilly, J.T. Hamm, P.J. Barrett-Lee, V. Cocquyt, K. Sideras, D.E. Young, C. Zhao, Y.L. Chia, U. Hoch, A.L. Hannah, E.A. Perez, Two schedules of etirinotecan pegol (NKTR-102) in patients with previously treated metastatic breast cancer: a randomised phase 2 study, The Lancet Oncology, 14 (2013) 12161225.

[14] G.S. Jameson, J.T. Hamm, G.J. Weiss, C. Alemany, S. Anthony, M. Basche, R.K. Ramanathan, M.J. Borad, R. Tibes, A. Cohn, I. Hinshaw, R. Jotte, L.S. Rosen, U. Hoch, M.A. Eldon, R. Medve, K. Schroeder, E. White, D.D. Von Hoff, A Multicenter, Phase I, Dose-Escalation Study to Assess the Safety, Tolerability, and Pharmacokinetics of Etirinotecan Pegol in Patients with Refractory Solid Tumors, Clinical Cancer Research, 19 (2013) 268-278.

[15] S. Eliasof, D. Lazarus, C.G. Peters, R.I. Case, R.O. Cole, J. Hwang, T. Schluep, J. Chao, J. Lin, Y. Yen, H. Han, D.T. Wiley, J.E. Zuckerman, M.E. Davis, Correlating preclinical animal studies and human clinical trials of a multifunctional, polymeric nanoparticle, Proceedings of the National Academy of Sciences, 110 (2013) 15127-15132.

[16] E. Pham, M.J. Birrer, S. Eliasof, E.G. Garmey, D. Lazarus, C.R. Lee, S. Man, U.A. Matulonis, C.G. Peters, P. Xu, C. Krasner, R.S. Kerbel, Translational impact of nanoparticle-drug conjugate CRLX101 with or without bevacizumab in advanced ovarian cancer, Clinical cancer research : an official journal of the American Association for Cancer Research, 21 (2015) 808-818.

[17] A.J. Clark, D.T. Wiley, J.E. Zuckerman, P. Webster, J. Chao, J. Lin, Y. Yen, M.E. Davis, CRLX101 nanoparticles localize in human tumors and not in adjacent, nonneoplastic tissue after intravenous dosing, Proceedings of the National Academy of Sciences, 113 (2016) 3850-3854.

[18] J.I. Hare, T. Lammers, M.B. Ashford, S. Puri, G. Storm, S.T. Barry, Challenges and strategies in anti-cancer nanomedicine development: An industry perspective, Advanced drug delivery reviews, (2016).

[19] H. Cabral, Y. Matsumoto, K. Mizuno, Q. Chen, M. Murakami, M. Kimura, Y. Terada, M.R. Kano, K. Miyazono, M. Uesaka, N. Nishiyama, K. Kataoka, Accumulation of sub-100 nm polymeric micelles in poorly permeable tumours depends on size, Nat. Nanotechnol., 6 (2011) 815-823.

[20] J. Yue, S. Liu, Z. Xie, Y. Xing, X. Jing, Size-dependent biodistribution and antitumour efficacy of polymer micelle drug delivery systems, J. Mater. Chem. B, 1 (2013) 4273-4280.

[21] J. Wang, W. Mao, L.L. Lock, J. Tang, M. Sui, W. Sun, H. Cui, D. Xu, Y. Shen, The Role of Micelle Size in Tumor Accumulation, Penetration, and Treatment, ACS Nano, 9 (2015) 7195-7206.

[22] D. Bhadra, S. Bhadra, S. Jain, N.K. Jain, A PEGylated dendritic nanoparticulate carrier of fluorouracil, International journal of pharmaceutics, 257 (2003) 111-124.

[23] D. Luo, K. Haverstick, N. Belcheva, E. Han, W.M. Saltzman, Poly(ethylene glycol)-Conjugated PAMAM Dendrimer for Biocompatible, High-Efficiency DNA Delivery, Macromolecules, 35 (2002) 3456-3462.

[24] H. Namazi, M. Adeli, Dendrimers of citric acid and poly (ethylene glycol) as the new drugdelivery agents, Biomaterials, 26 (2005) 1175-1183.

[25] P. Singh, U. Gupta, A. Asthana, N.K. Jain, Folate and folate-PEG-PAMAM dendrimers: synthesis, characterization, and targeted anticancer drug delivery potential in tumor bearing mice, Bioconjugate chemistry, 19 (2008) 2239-2252.

[26] L.M. Kaminskas, B.D. Kelly, V.M. McLeod, G. Sberna, B.J. Boyd, D.J. Owen, C.J. Porter, Capping methotrexate alpha-carboxyl groups enhances systemic exposure and retains the cytotoxicity of drug conjugated PEGylated polylysine dendrimers, Molecular pharmaceutics, 8 (2011) 338-349.

[27] L.M. Kaminskas, B.J. Boyd, C.J. Porter, Dendrimer pharmacokinetics: the effect of size, structure and surface characteristics on ADME properties, Nanomedicine, 6 (2011) 1063-1084. 
[28] L.M. Kaminskas, B.J. Boyd, P. Karellas, G.Y. Krippner, R. Lessene, B. Kelly, C.J. Porter, The impact of molecular weight and PEG chain length on the systemic pharmacokinetics of PEGylated poly Ilysine dendrimers, Molecular pharmaceutics, 5 (2008) 449-463.

[29] T. Okuda, S. Kawakami, T. Maeie, T. Niidome, F. Yamashita, M. Hashida, Biodistribution characteristics of amino acid dendrimers and their PEGylated derivatives after intravenous administration, Journal of Controlled Release, 114 (2006) 69-77.

[30] T. Wei, C. Chen, J. Liu, C. Liu, P. Posocco, X. Liu, Q. Cheng, S. Huo, Z. Liang, M. Fermeglia, S. Pricl, X.J. Liang, P. Rocchi, L. Peng, Anticancer drug nanomicelles formed by self-assembling amphiphilic dendrimer to combat cancer drug resistance, Proceedings of the National Academy of Sciences of the United States of America, 112 (2015) 2978-2983.

[31] H. Cai, K. Li, J. Li, S. Wen, Q. Chen, M. Shen, L. Zheng, G. Zhang, X. Shi, Dendrimer-Assisted Formation of Fe304/Au Nanocomposite Particles for Targeted Dual Mode CT/MR Imaging of Tumors, Small, 11 (2015) 4584-4593.

[32] L.Y. Lim, P.Y. Koh, S. Somani, M. Al Robaian, R. Karim, Y.L. Yean, J. Mitchell, R.J. Tate, R. EdradaEbel, D.R. Blatchford, M. Mullin, C. Dufes, Tumor regression following intravenous administration of lactoferrin- and lactoferricin-bearing dendriplexes, Nanomedicine, 11 (2015) 1445-1454.

[33] Q. Zhong, E.R. Bielski, L.S. Rodrigues, M.R. Brown, J.J. Reineke, S.R. da Rocha, Conjugation to Poly(amidoamine) Dendrimers and Pulmonary Delivery Reduce Cardiac Accumulation and Enhance Antitumor Activity of Doxorubicin in Lung Metastasis, Molecular pharmaceutics, 13 (2016) 23632375.

[34] R.M. England, J.I. Hare, P.D. Kemmitt, K.E. Treacher, M.J. Waring, S.T. Barry, C. Alexander, M. Ashford, Enhanced cytocompatibility and functional group content of poly(I-lysine) dendrimers by grafting with poly(oxazolines), Polymer Chemistry, 7 (2016) 4609-4617.

[35] S. Ashton, Y.H. Song, J. Nolan, E. Cadogan, J. Murray, R. Odedra, J. Foster, P.A. Hall, S. Low, P. Taylor, R. Ellston, U.M. Polanska, J. Wilson, C. Howes, A. Smith, R.J.A. Goodwin, J.G. Swales, N. Strittmatter, Z. Takáts, A. Nilsson, P. Andren, D. Trueman, M. Walker, C.L. Reimer, G. Troiano, D. Parsons, D. De Witt, M. Ashford, J. Hrkach, S. Zale, P.J. Jewsbury, S.T. Barry, Aurora kinase inhibitor nanoparticles target tumors with favorable therapeutic index in vivo, Science Translational Medicine, 8 (2016) 325ra317-325ra317.

[36] P. Chytil, S. Hoffmann, L. Schindler, L. Kostka, K. Ulbrich, H. Caysa, T. Mueller, K. Mader, T. Etrych, Dual fluorescent HPMA copolymers for passive tumor targeting with $\mathrm{pH}$-sensitive drug release II: impact of release rate on biodistribution, J. Control. Release, 172 (2013) 504-512.

[37] R. Duncan, M.J. Vicent, Polymer therapeutics-prospects for 21st century: the end of the beginning, Adv. Drug Deliv. Rev., 65 (2013) 60-70.

[38] J. Kopecek, Polymer-drug conjugates: origins, progress to date and future directions, Adv. Drug Deliv. Rev., 65 (2013) 49-59.

[39] G.W. Ashley, J. Henise, R. Reid, D.V. Santi, Hydrogel drug delivery system with predictable and tunable drug release and degradation rates, Proc. Natl. Acad. Sci. U. S. A., 110 (2013) 2318-2323.

[40] Q. Hu, E.V. van Gaal, P. Brundel, H. Ippel, T. Hackeng, C.J. Rijcken, G. Storm, W.E. Hennink, J. Prakash, A novel approach for the intravenous delivery of leuprolide using core-cross-linked polymeric micelles, J. Control. Release, 205 (2015) 98-108.

[41] S.A. Raw, An improved process for the synthesis of DMTMM-based coupling reagents, Tetrahedron Letters, 50 (2009) 946-948.

[42] N. Abbassi-Ghadi, E.A. Jones, K.A. Veselkov, J. Huang, S. Kumar, N. Strittmatter, O. Golf, H. Kudo, R.D. Goldin, G.B. Hanna, Z. Takats, Repeatability and reproducibility of desorption electrospray ionization-mass spectrometry (DESI-MS) for the imaging analysis of human cancer tissue: a gateway for clinical applications, Analytical Methods, 7 (2015) 71-80.

[43] T. Schramm, A. Hester, I. Klinkert, J.-P. Both, R.M.A. Heeren, A. Brunelle, O. Laprévote, N. Desbenoit, M.-F. Robbe, M. Stoeckli, B. Spengler, A. Römpp, imzML - A common data format for the flexible exchange and processing of mass spectrometry imaging data, Journal of Proteomics, 75 (2012) 5106-5110. 
[44] G. Robichaud, K.P. Garrard, J.A. Barry, D.C. Muddiman, MSiReader: An Open-Source Interface to View and Analyze High Resolving Power MS Imaging Files on Matlab Platform, Journal of The American Society for Mass Spectrometry, 24 (2013) 718-721.

[45] R.B. Greenwald, A. Pendri, C.D. Conover, C. Lee, Y.H. Choe, C. Gilbert, A. Martinez, J. Xia, D. Wu, M. Hsue, Camptothecin-20-PEG ester transport forms: the effect of spacer groups on antitumor activity, Bioorganic \& medicinal chemistry, 6 (1998) 551-562.

[46] K. Lava, B. Verbraeken, R. Hoogenboom, Poly(2-oxazoline)s and click chemistry: A versatile toolbox toward multi-functional polymers, European Polymer Journal, 65 (2015) 98-111.

[47] F. Koizumi, M. Kitagawa, T. Negishi, T. Onda, S.-i. Matsumoto, T. Hamaguchi, Y. Matsumura, Novel SN-38-Incorporating Polymeric Micelles, NK012, Eradicate Vascular Endothelial Growth Factor-Secreting Bulky Tumors, Cancer research, 66 (2006) 10048-10056.

[48] C.E. Adkins, M.I. Nounou, T. Hye, A.S. Mohammad, T. Terrell-Hall, N.K. Mohan, M.A. Eldon, U. Hoch, P.R. Lockman, NKTR-102 Efficacy versus irinotecan in a mouse model of brain metastases of breast cancer, BMC Cancer, 15 (2015) 685.

[49] A.K. Ghosh, M. Brindisi, Organic Carbamates in Drug Design and Medicinal Chemistry, Journal of Medicinal Chemistry, 58 (2015) 2895-2940.

[50] H.H. Gustafson, D. Holt-Casper, D.W. Grainger, H. Ghandehari, Nanoparticle Uptake: The Phagocyte Problem, Nano today, 10 (2015) 487-510.

[51] J.P. Armand, CPT-11: clinical experience in phase I studies, Seminars in oncology, 23 (1996) 2733.

[52] S. Chen, M.-F. Yueh, C. Bigo, O. Barbier, K. Wang, M. Karin, N. Nguyen, R.H. Tukey, Intestinal glucuronidation protects against chemotherapy-induced toxicity by irinotecan (CPT-11), Proceedings of the National Academy of Sciences, 110 (2013) 19143-19148.

[53] S. Turcotte, L. Sideris, R. Younan, P. Drolet, P. Dube, Pharmacokinetics of intraperitoneal irinotecan in a pig model, Journal of surgical oncology, 101 (2010) 637-642.

[54] Y. Machida, H. Onishi, A. Kurita, H. Hata, A. Morikawa, Y. Machida, Pharmacokinetics of prolonged-release CPT-11-loaded microspheres in rats, Journal of controlled release : official journal of the Controlled Release Society, 66 (2000) 159-175. 